\title{
Geohazard Caused by Groundwater in Urban Underground Excavation
}

\author{
Bin-Chen Benson Hsiung (D) \\ Department of Civil Engineering, National Kaohsiung University of Sciences and Technology, 415, Chen Kung Road, \\ Kaohsiung 807, Taiwan \\ Correspondence should be addressed to Bin-Chen Benson Hsiung; benson.hsiung@gmail.com
}

Received 15 April 2018; Revised 4 July 2018; Accepted 29 August 2018; Published 7 November 2018

Academic Editor: Guan-Wei Lin

Copyright (C) 2018 Bin-Chen Benson Hsiung. This is an open access article distributed under the Creative Commons Attribution License, which permits unrestricted use, distribution, and reproduction in any medium, provided the original work is properly cited.

\begin{abstract}
This paper addresses the important role of water in geohazard and failure in urban underground excavation. These so-called underground water-related hazards, such as leakage of the tunnel eye due to launching and docking of the shield, failure of the cross-passage excavation, and failure of the retaining wall caused by water ingress for deep excavation, often lead to catastrophic disasters. Leakage of the tunnel eye during shield launching that results in failure was selected for further analysis using finite element simulations. According to this work, the flush-in of water mainly leads to the failure of soils located at the invert of the tunnel immediately behind the wall, and gravity is the cause of such failure phenomena; these findings agree with field observations. A significant reduction in the pore pressure of soils behind the wall associated with water relief through the tunnel eye and the quantity of water flow into the excavation is predicted. Piping failure is also suggested to occur during shield launching under the current arrangements. Finally, according to parametric studies, reducing the soil permeability and increasing the cohesion force are recommended to prevent the opportunity for failure.
\end{abstract}

\section{Introduction}

Modern underground excavations are frequently utilised to expand the underground space in modern cities, and deep excavations and tunnelling are used as tools for the construction of urban underground spaces. However, such large-scale excavations often lead to accidents that cause the loss of property and human life. These accidents and hazards are frequently connected with groundwater. Despite this fact, studies of such collapse and hazards in the geotechnical aspects of urban underground excavation are mainly focused on observations, mitigation measures, and the possible reasons leading to hazards based on case histories of previous studies. In this paper, in contrast to previous studies, modelling and the mechanism of geohazards due to groundwater in urban underground excavations (mainly deep excavation and tunnelling in highly permeable ground with a high ground water level) are provided and discussed. The roles of water in the failure mechanism, the pore pressure distribution and changes, the groundwater flow direction, and the quantity of water flow caused by launching the shield are included in the simulation. Finally, the impacts of the permeability, strength, and stiffness of improved soils on the failure of soils are also examined.

\section{Geohazards Caused by Groundwater in Cases of Urban Underground Excavation}

Wagner and Knights [1] highlighted the geohazard and risk management of underground construction and stated that the financial losses from 15 major tunnels within 10 years exceeds USD 500 million. To minimise the risks due to underground construction activities, many professions and organisations, such as the British Tunnel Society [2], Eskeren et al. [3], GEO [4], and The International Tunnelling Insurance Group [5], have proposed a variety of follow-up guidelines or codes of practice. At the same time, using the metro system as an example, Moh and Hwang [6] indicated 23 major accidents during the construction of urban underground infrastructure from 2001 to 2006 in the Asia Pacific 
TABle 1: Significant accidents in construction of underground metro system caused by groundwater in Asia Pacific region from 2001 to 2006.

\begin{tabular}{|c|c|c|}
\hline Locations & Causes & Consequence \\
\hline Taipei, Taiwan & Leakage of tunnel eye & More than 100 residential houses damaged \\
\hline Shanghai, China & Failure of cross passage & Collapse or tilting of several buildings \\
\hline Kaohsiung, Taiwan & Leakage of tunnel eye & Seven buildings damaged and 40 families evacuated \\
\hline Kaohsiung, Taiwan & Leakage of diaphragm wall & A nearby hospital was endangered \\
\hline Guangzhou, China & $\begin{array}{c}\text { Rupture of water main led to collapse of } \\
\text { diaphragm wall }\end{array}$ & $\begin{array}{l}3 \text { persons fell into sinkhole and one person } \\
\text { severely injured }\end{array}$ \\
\hline Taipei, Taiwan & Rupture of water main & A large sinkhole \\
\hline Taipei, Taiwan & Leakage of tunnel eye & A large sinkhole \\
\hline Kaohsiung, Taiwan & Leakage of diaphragm wall & 4 buildings collapsed and 3 buildings severely damaged \\
\hline Kaohsiung, Taiwan & Failure of cross passage & $\begin{array}{l}\text { The tunnel, together with the underpass above the tunnel, } \\
\text { about } 100 \mathrm{~m} \text { in length were totally damaged }\end{array}$ \\
\hline Beijing, China & Rupture of sewer & A large sinkhole \\
\hline
\end{tabular}

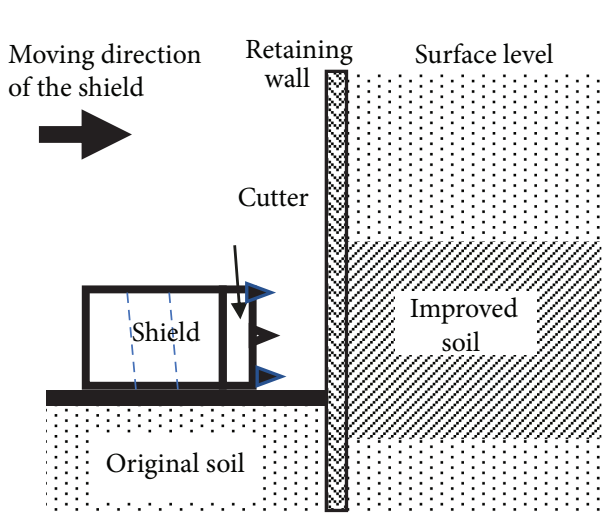

Assemble of the shield in the pit

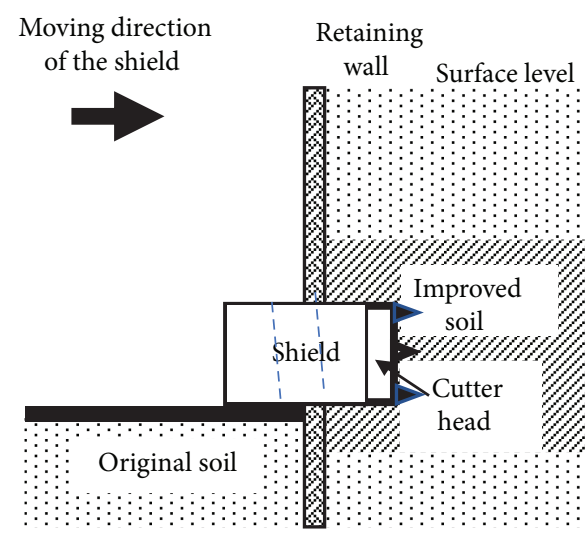

Launching of the shield in the pit

(a) Schematic drawing of launching of a shield

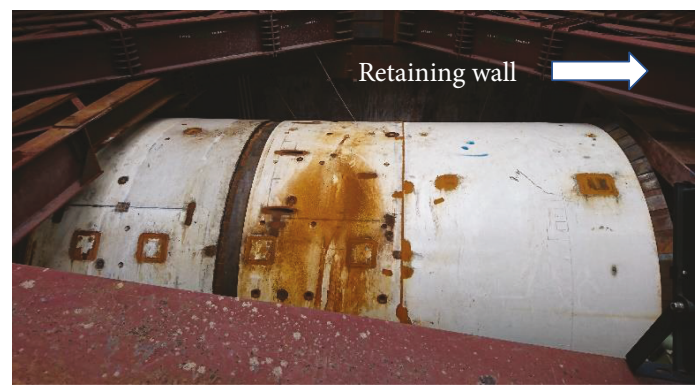

Moving direction

of the shield

(b) The shield in the pit

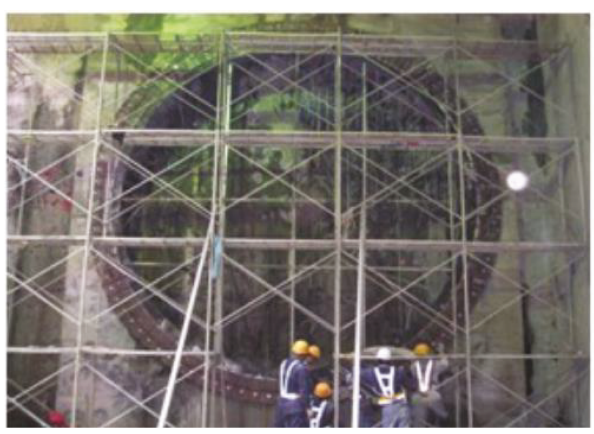

(c) Tunnel eye for launching

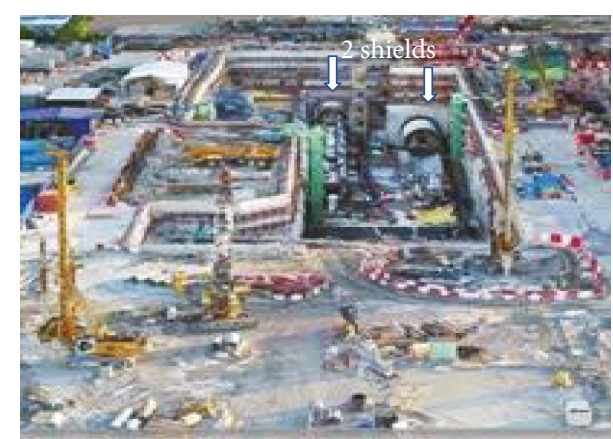

(d) Launching of shields

FIgURE 1: The launching of a shield. 


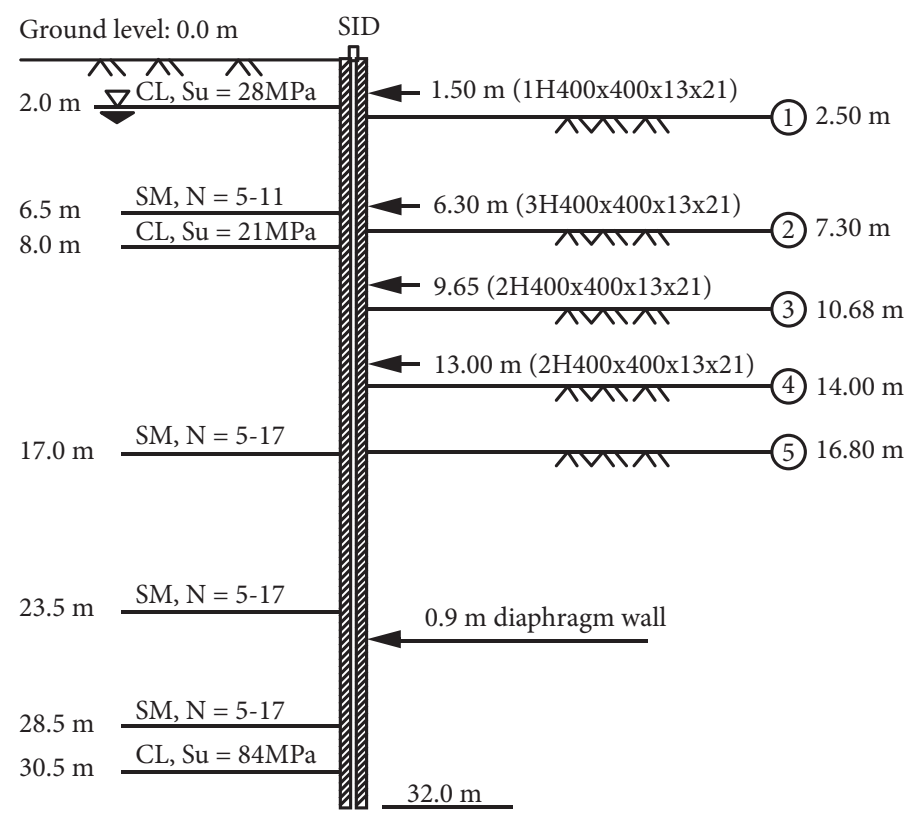

$42.0 \mathrm{~m} \quad \mathrm{SM}, \mathrm{N}=18-262$

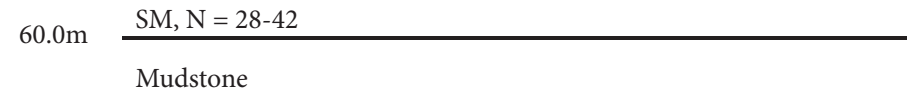

Figure 2: Cross section and ground profile of the excavation.

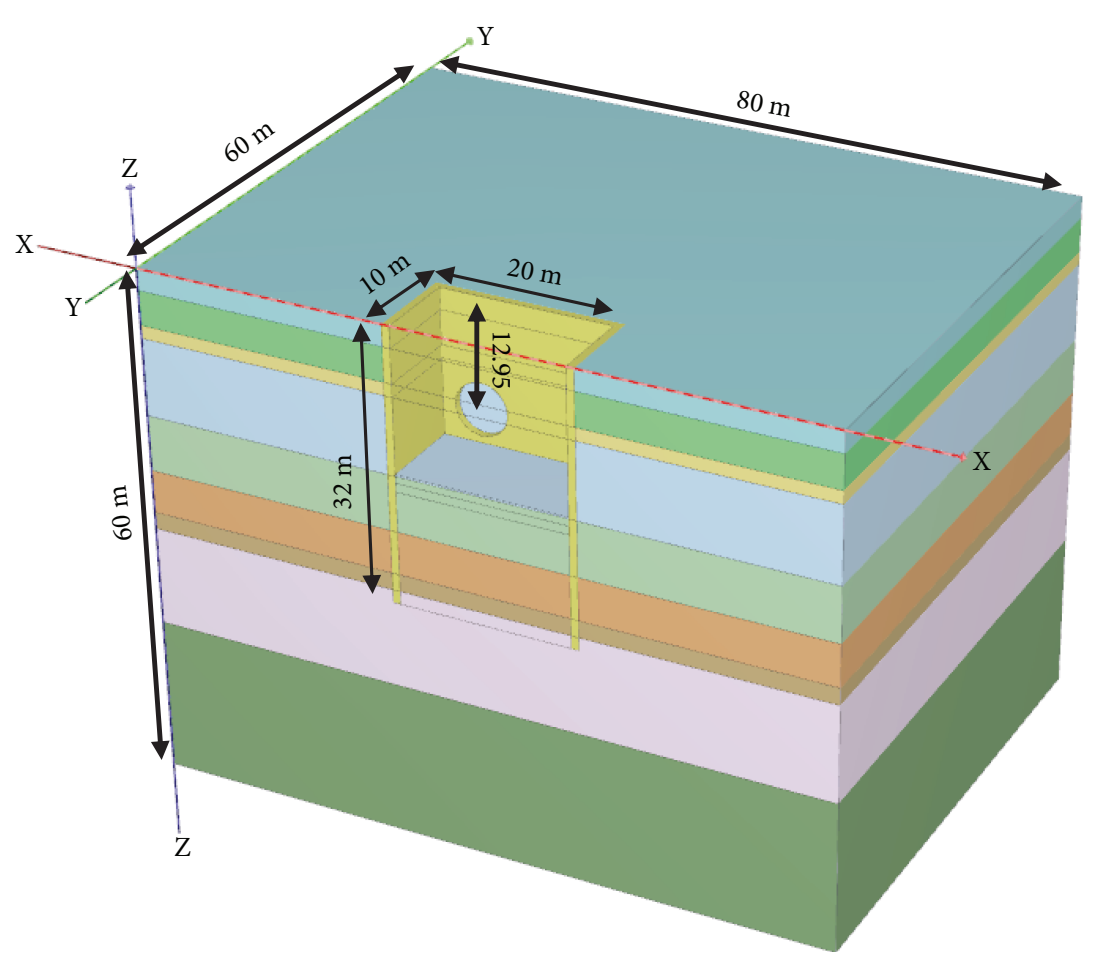

Figure 3: 3-dimensional model of simulation of launching of a shield. 

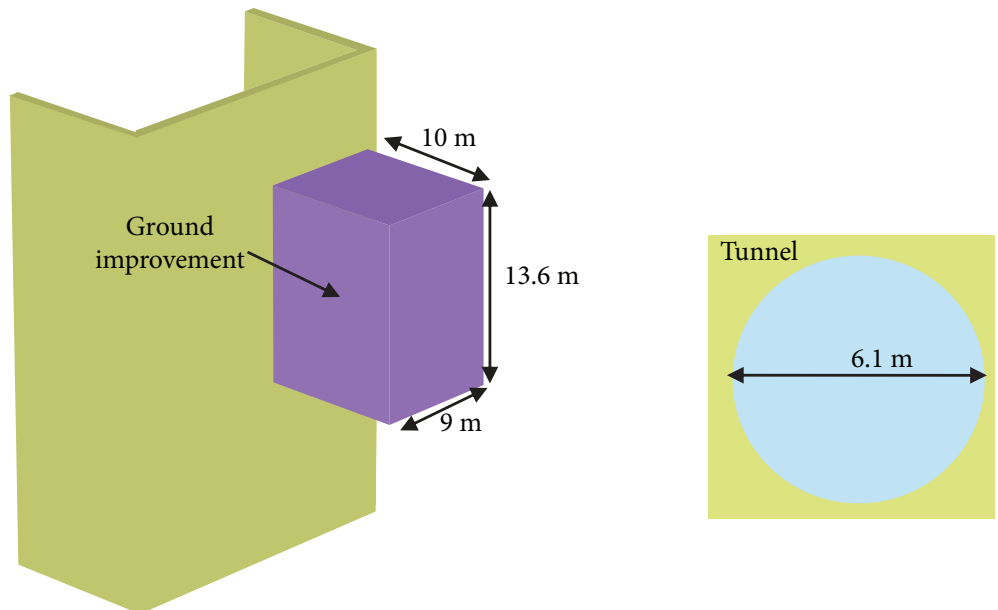

Figure 4: Details of tunnel eye and soil improvement zone in the model.

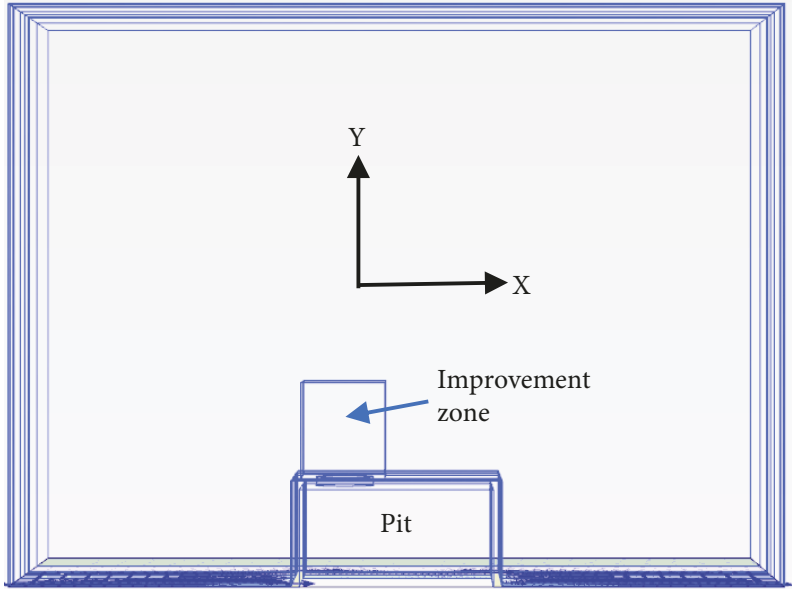

(a)

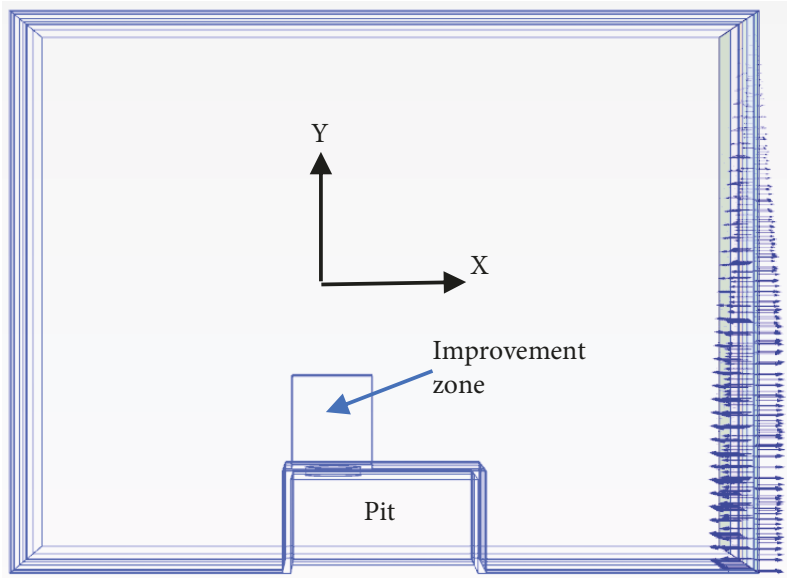

(c)

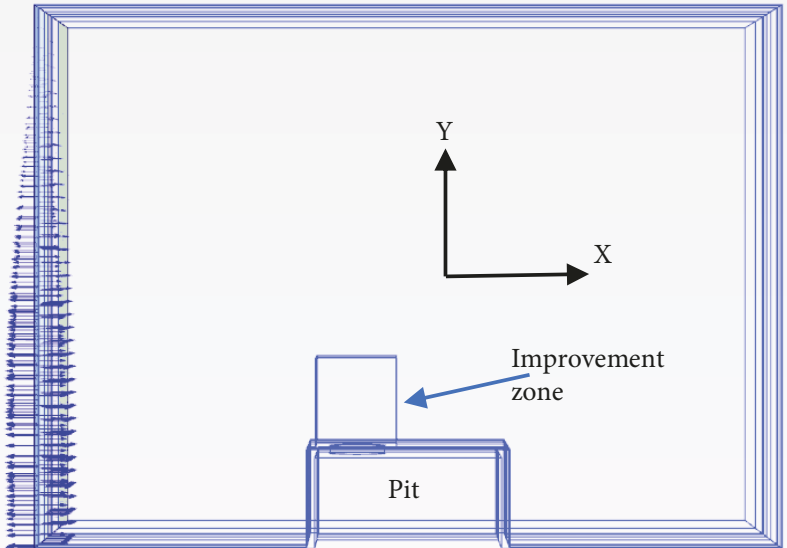

(b)

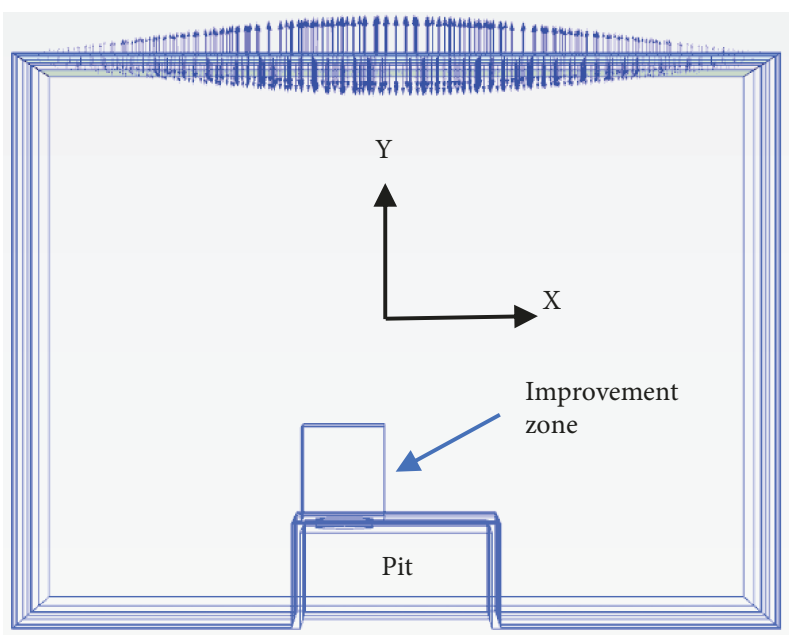

(d)

FIGURE 5: Boundaries conditions of water in the model (Plane view). (a) $\mathrm{Y}_{\min }$ closed; (b) $\mathrm{X}_{\min }$ opened; (c) $\mathrm{X}_{\max }$ opened; and (d) $\mathrm{Y}_{\max }$ opened.

region and, among them, estimated that 10 were directly caused by groundwater, which is a very high proposition, as listed in Table 1. As categorised by Moh and Hwang [6], the geohazards related to groundwater for urban underground excavations are stated in Table 1 and include leakage at the tunnel eye (via launching or docking of the shield in 
TABLE 2: Input parameters of soils and structures.

(a) Sandy soil (hardening soil with small strain)

\begin{tabular}{lccccccc}
\hline Layer & Depth $(\mathrm{m})$ & Drainage type & Unit weight $\left(\mathrm{kN} / \mathrm{m}^{3}\right)$ & $\phi^{\prime}\left({ }^{\circ}\right)$ & $\mathrm{E}_{50}^{\text {ref }}(\mathrm{kPa})$ & $\mathrm{K} 0$ & $\mathrm{G}_{0}^{\text {ref }}\left(\mathrm{kN} / \mathrm{m}^{2}\right)$ \\
\hline 2 & $2.0-6.5$ & Drained & 20.9 & 32 & $26.22 \times 10^{3}$ & 0.4701 & $1.44 \times 10^{5}$ \\
4 & $8.0-17.0$ & Drained & 20.6 & 32 & $21.9 \times 10^{3}$ & 0.4701 & $1.41 \times 10^{5}$ \\
5 & $17.0-23.5$ & Drained & 18.6 & 32 & $24.06 \times 10^{3}$ & 0.4701 & $1.41 \times 10^{5}$ \\
6 & $23.5-28.5$ & Drained & 19.6 & 33 & $26.25 \times 10^{3}$ & 0.4554 & $1.6 \times 10^{5}$ \\
8 & $30.5-42$ & Drained & 19.6 & 34 & $29.58 \times 10^{3}$ & 0.4408 & $1.62 \times 10^{5}$ \\
9 & $42-60$ & Drained & 19.6 & 34 & $33.15 \times 10^{3}$ & 0.4408 & $1.77 \times 10^{5}$ \\
\hline
\end{tabular}

Note: $v^{\prime}=0.3 ; \gamma_{0.7}=1 \times 10^{-4} ; \mathrm{E}_{\mathrm{ur}}^{\text {ref }}=3 \mathrm{E}_{50} \stackrel{\text { ref }}{\mathrm{E}_{\text {oed }}}{ }^{\text {ref }}=\mathrm{E}_{50} \stackrel{\text { ref }}{;} \mathrm{m}=0.5 ;$ permeability $=2 \times 10^{-4} \mathrm{~cm} / \mathrm{sec} ; \mathrm{Rf}=0.9$.

(b) Clay (Mohr-Coulomb)

\begin{tabular}{lcccccccc}
\hline Layer & Depth $(\mathrm{m})$ & Soil type & $\gamma\left(\mathrm{kN} / \mathrm{m}^{3}\right)$ & $S_{u}(\mathrm{kPa})$ & $\mathrm{E}^{\prime}(\mathrm{kPa})$ & $v^{\prime}$ & $\mathrm{K} 0$ & Permeability $(\mathrm{cm} / \mathrm{sec})$ \\
\hline 1 & $0.0-2.0$ & $\mathrm{CL}$ & 19.3 & 28 & 13,060 & 0.3947 & 1.0 & $1 \times 10^{-8}$ \\
3 & $6.5-8.0$ & CL & 19.7 & 21 & 9800 & 0.3953 & 1.0 & $1 \times 10^{-8}$ \\
7 & $28.0-30.5$ & CL & 18.6 & 84 & 39,200 & 0.3953 & 1.0 & $1 \times 10^{-8}$ \\
\hline
\end{tabular}

(c) Improvement soils

\begin{tabular}{lcccccccc}
\hline Depth $(\mathrm{m})$ & Drainage type & $\gamma\left(\mathrm{kN} / \mathrm{m}^{3}\right)$ & $\mathrm{c}^{\prime}\left(\mathrm{kN} / \mathrm{m}^{3}\right)$ & $\phi^{\prime}\left({ }^{\circ}\right)$ & $\mathrm{E}^{\prime}(\mathrm{kPa})$ & $v^{\prime}$ & K0 & Permeability $(\mathrm{cm} / \mathrm{sec})$ \\
\hline $10.0-16.0$ & Undrained & 21 & 100 & 34 & 120,000 & 0.3 & 0.44 & $1 \times 10^{-6}$ \\
\hline
\end{tabular}

${ }^{\#}$ Using the function of UC test implemented in PLAXIS, an equivalent undrained shear strength (Su) of routed sand is thus defined. Through an empirical approach [15], an assumption of $\mathrm{Eu}=500 \mathrm{Su}$ is adopted to determine the undrained Young's modulus (Eu). Effective soil stiffness $\mathrm{E}^{\prime}$ is required to be applied in the analyses so an equation of $E^{\prime}=2\left(1+v^{\prime}\right) / 3 \times E u$ is used to determine $E^{\prime}\left(0.3\right.$ of $v^{\prime}$ is used). * In engineering practice, standard requirement of improved soils outside the pit for launching of shield is in the range of $1 \times 10^{-5}$ to $1 \times 10^{-6} \mathrm{~cm} / \mathrm{sec}$ but tends to be stricter $\left(1 \times 10^{-6} \mathrm{~cm} / \mathrm{sec}\right)$ for highly permeable ground (such as sand) with high ground water level to reduce the risk [16].

(d) Retaining structure

\begin{tabular}{lccc}
\hline Parameter & Name & Value & \\
\hline Compressive strength of concrete & $f_{c}^{\prime}$ & 28 & Unit \\
Thickness & $d$ & 0.9 & $\mathrm{MPa}$ \\
Young's modulus & $E$ & $24.8 \times 10^{6}$ & $\mathrm{~m}$ \\
Young's modulus x 70\% & $70 \% E$ & $17.36 \times 10^{6}$ & $\mathrm{kPa}$ \\
Unit weight & $w$ & 5.5 & $\mathrm{kPa}$ \\
Poisson's ratio & $v$ & 0.2 & $\mathrm{kN} / \mathrm{m}^{3}$ \\
\hline
\end{tabular}

(e) Steel strut

\begin{tabular}{|c|c|c|c|c|c|}
\hline Strut level & Strut level & Preload (kN) & Section area $\left(\mathrm{m}^{2}\right)$ & $E A(\mathrm{kN})$ & $60 \% E A(\mathrm{kN})$ \\
\hline Level 1 & $1 \mathrm{H} 400 \mathrm{x} 400 \mathrm{x} 13 \times 21$ & 450 & 0.0219 & $4.59 \times 10^{6}$ & $2.75 \times 10^{6}$ \\
\hline Level 2 & $2 \mathrm{H} 400 \times 400 \times 13 \times 21$ & 1000 & 0.0437 & $9.18 \times 10^{6}$ & $5.50 \times 10^{6}$ \\
\hline Level 3 & $2 \mathrm{H} 400 \times 400 \times 13 \times 21$ & 1400 & 0.0437 & $9.18 \times 10^{6}$ & $5.50 \times 10^{6}$ \\
\hline Level 4 & $2 \mathrm{H} 400 \times 400 \times 13 \times 21$ & 1400 & 0.0437 & $9.18 \times 10^{6}$ & $5.50 \times 10^{6}$ \\
\hline
\end{tabular}

the shaft), failure of cross-passage excavation in the tunnelling process, and failure of the retaining wall or diaphragm wall caused by water ingress during deep excavations as well as rupture of water mains or sewers caused by the nearby construction activity of deep excavations or tunnelling. Through risk assessment, the geohazards stated above for urban underground excavations are recognised as high-risk activities and could lead to severe damage. However, none
TABLE 3: Construction sequence in simulation.

\begin{tabular}{lc}
\hline Phase number & Construction activities \\
\hline 0 & Initial stress generation \\
1 & Wall installation \\
2 & Main excavation \\
3 & Ground improvement \\
4 & Launching of the shield \\
\hline
\end{tabular}



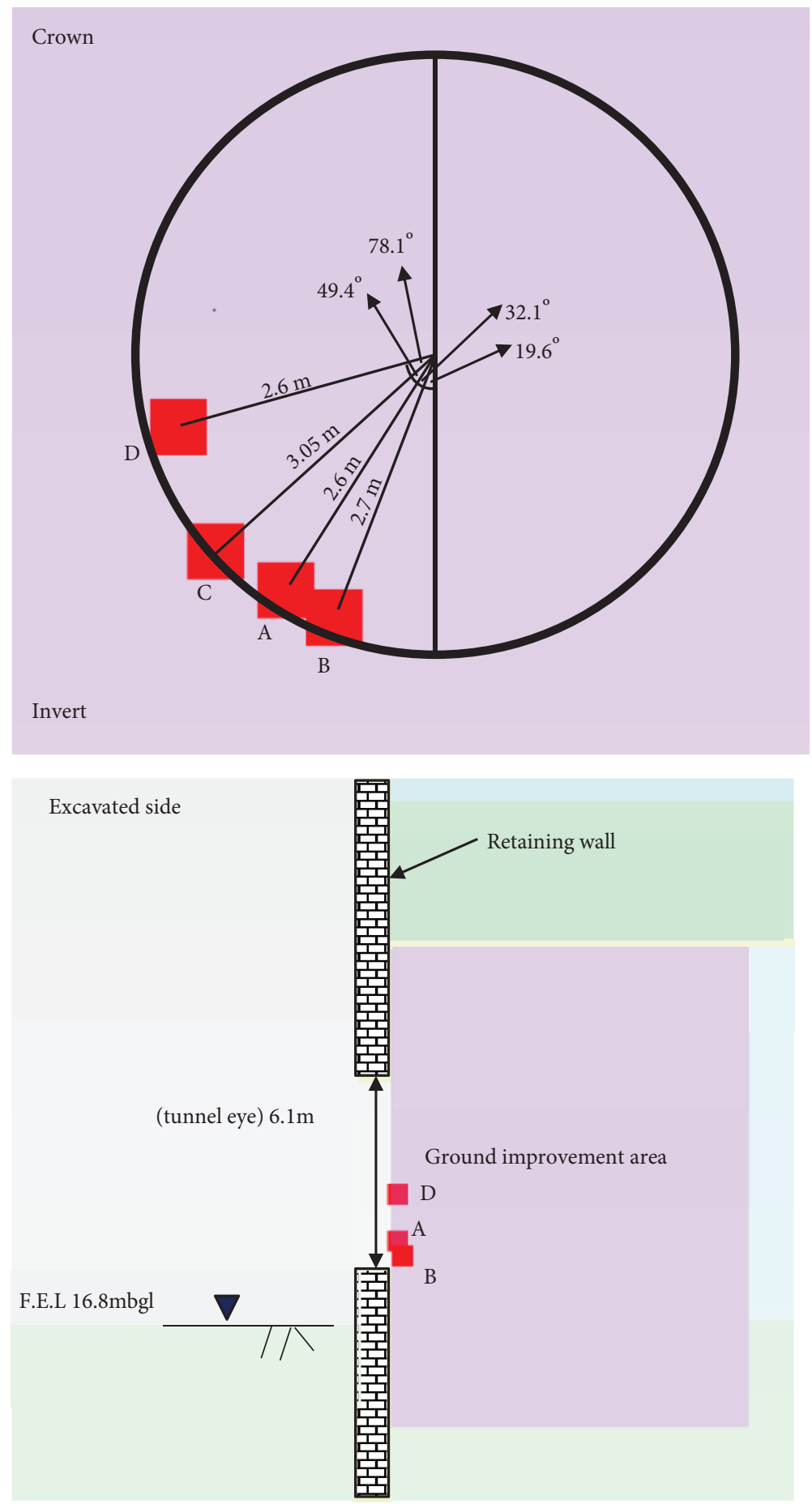

FiguRE 6: Failure points during the launching of a shield (transverse section immediately behind the wall).

of the literature has previously stated how to access and quantify the impact of groundwater on failure using numerical technologies, especially for highly permeable ground with a high groundwater level.

Considering the statements above, fatal failures caused by the groundwater during urban underground excavation and the launching of the shield in the shaft are further analysed and discussed in this paper. In addition, the impacts of the permeability, strength, and stiffness of improved soils on failure are examined.

\section{Construction Background and Analytical Approaches}

The construction background associated with launching of a shield in a working shaft is introduced first. In an 
$\left(\mathrm{kN} / \mathrm{m}^{2}\right)$

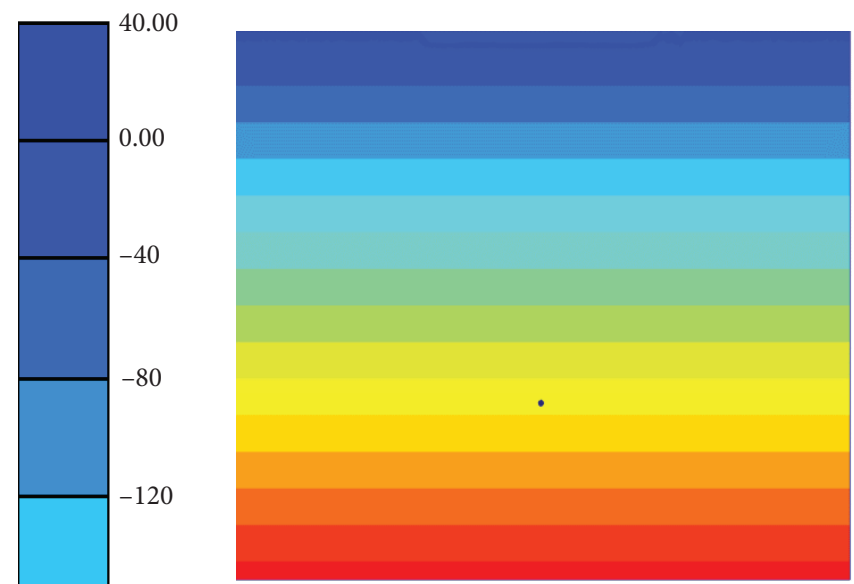

(a)

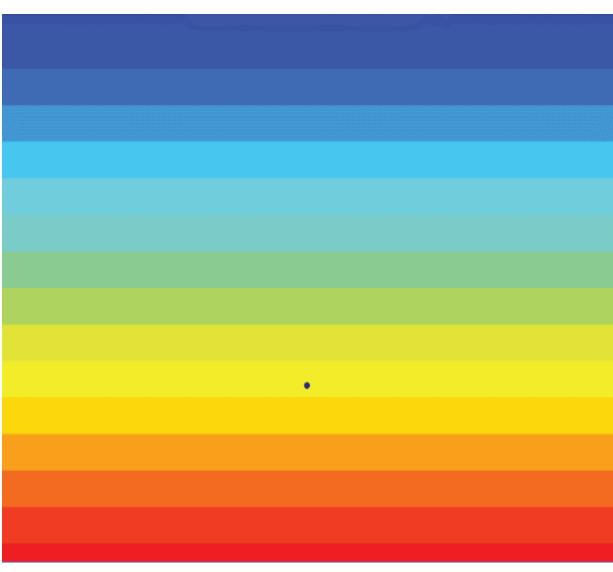

(b)

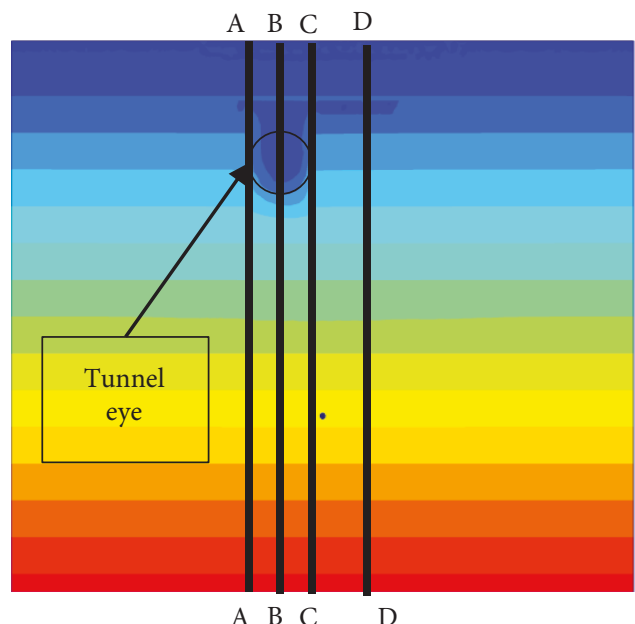

(c)
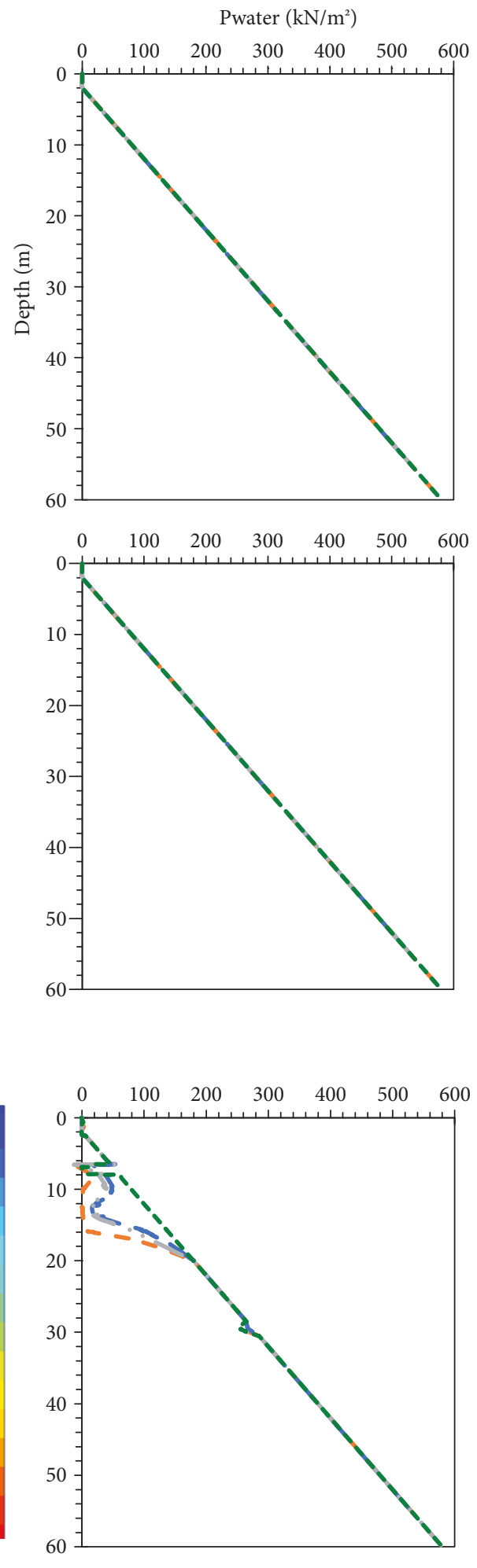

$$
--\mathrm{A}-\mathrm{A} \quad-\cdots \mathrm{C}-\mathrm{C}
$$

Figure 7: Change of pore pressure distribution at various depths and locations at different phases of launching of a shield in transverse direction. (a) Initial phase. (b) Main excavation. (c) Launching of the shield. Note: A-A: left side of tunnel eye; B-B: center of tunnel; C-C: right side of tunnel eye; and D-D: $5 \mathrm{~m}$ away from the right side corner. "-"in pore pressure distribution contour is positive pore pressure and "Pwater" means pore pressure. 


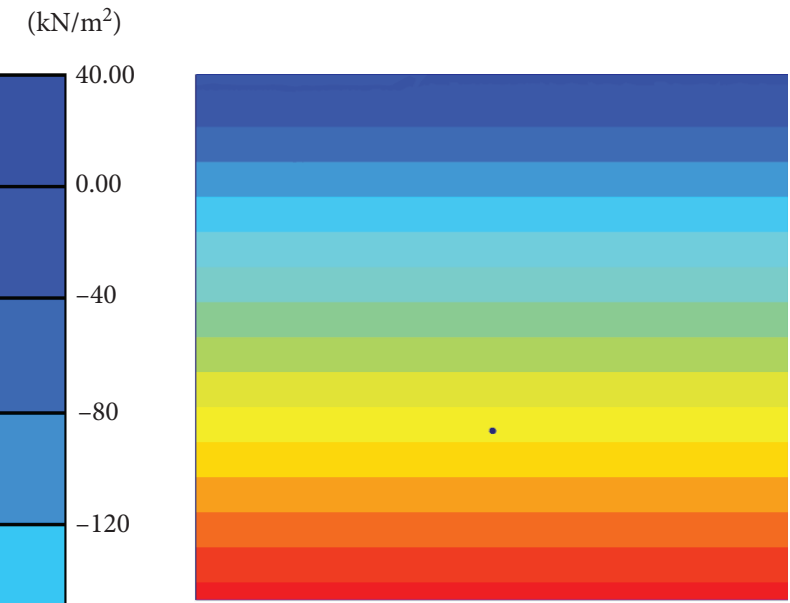

(a)

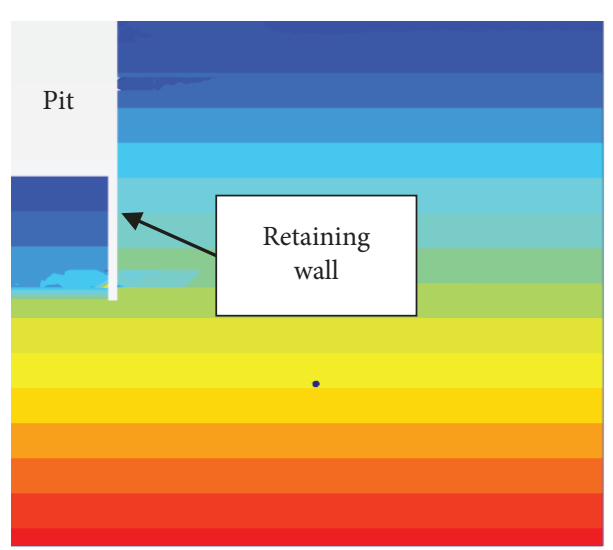

(b)

$-400$

$-440$

$-480$

$-520$

-560
-600
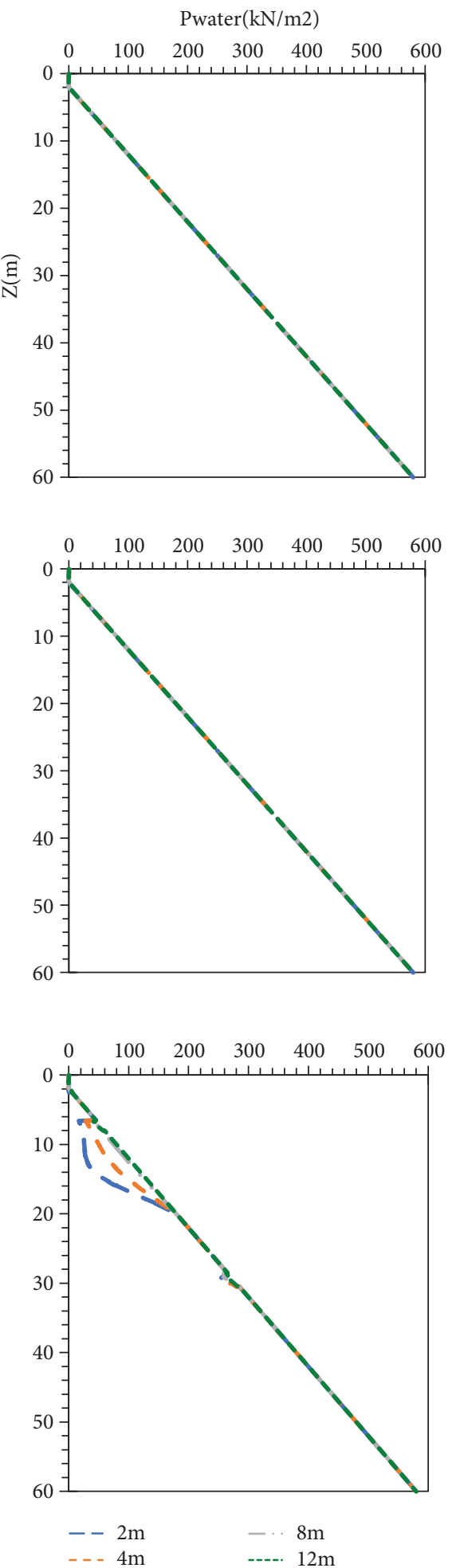

Figure 8: Change of pore pressure distribution at various depths and locations at different phases of launching of a shield in longitudinal direction. (a) Initial phase. (b) Main excavation. (c) Launching of the shield. Note: legend means points at various distance from the retaining wall and "-" in pore pressure distribution contour is positive pore pressure. "Pwater" means pore pressure.

urban underground infrastructure system, very often, shield-machine bored tunnels are adopted instead of cut-and-cover tunnels to reduce the interruption of traffic and daily life of the population on the surface level. To initiate tunnelling, the working shafts must be constructed at two ends of the tunnels to allow the shield to be 


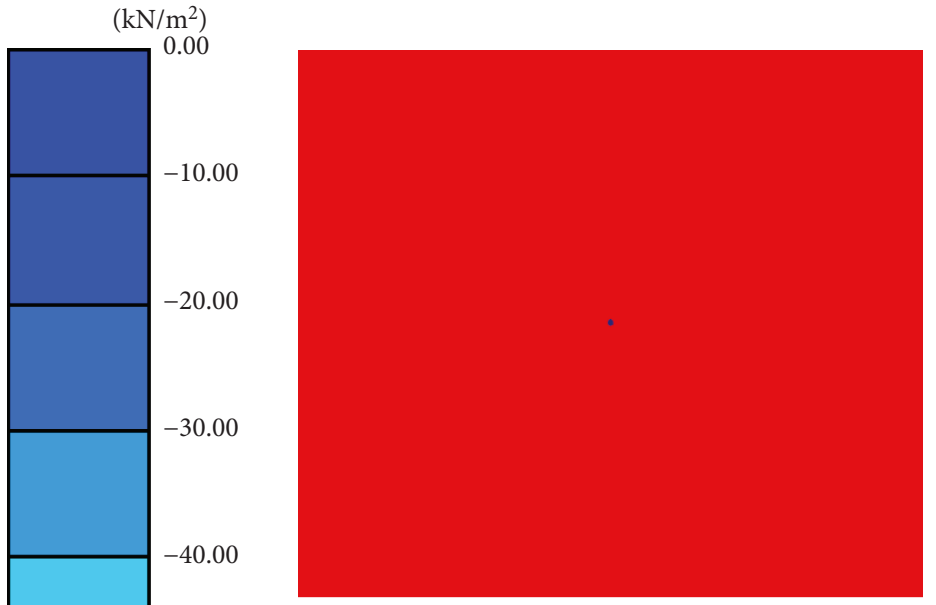

(a)

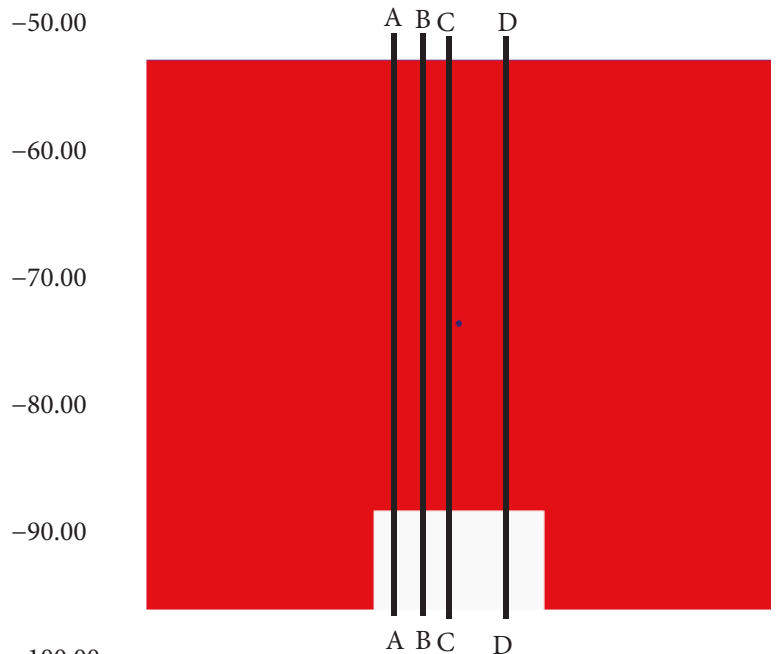

(b)

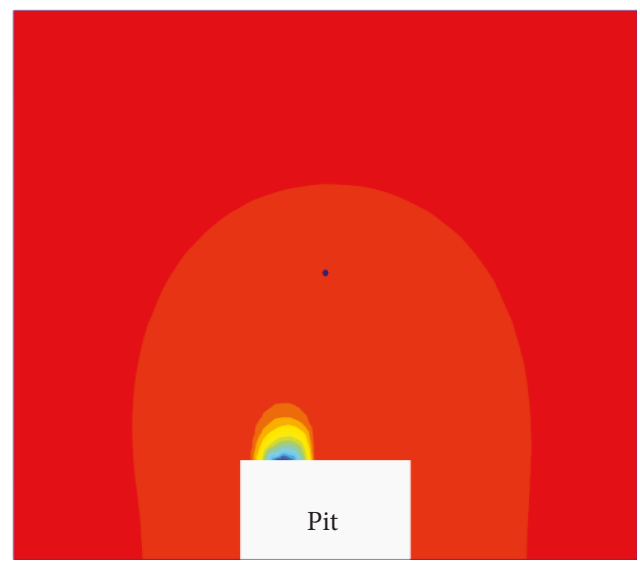

(c)

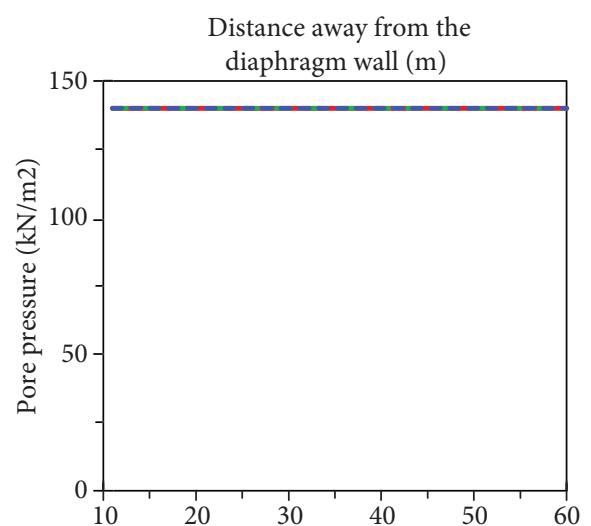

- Cross section A-A - - - Cross section C-C - Cross section B-B ---- Cross section D-D

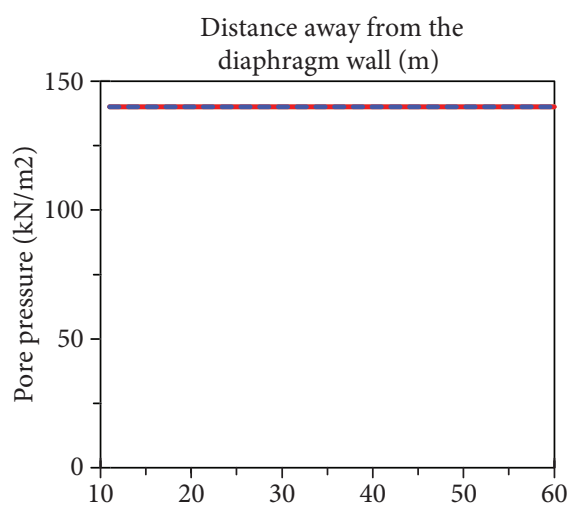

- Cross section A-A - Cross section C-C - Cross section B-B ---- Cross section D-D

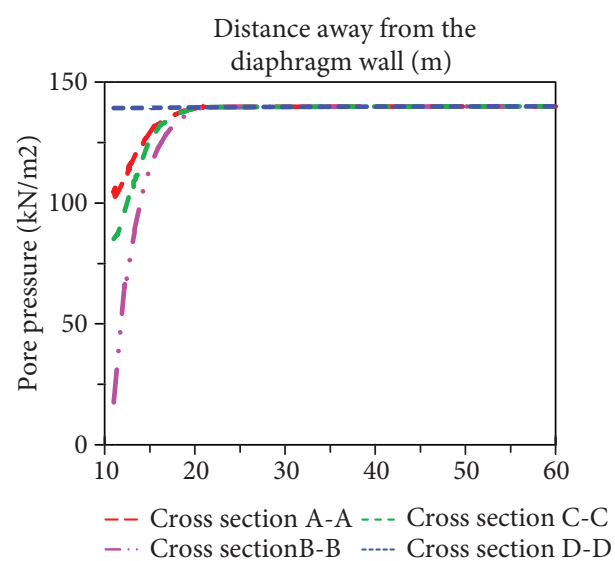

Figure 9: Change of pore pressure at various depths and locations at different phases of launching of a shield in plane view at $16 \mathrm{mbgl}$. (a) Initial phase. (b) Main excavation. (c) Launching of the shield. Note: A-A: left side of tunnel eye; B-B: center of tunnel; C-C: right side of tunnel eye; and D-D: $5 \mathrm{~m}$ away from the right side corner and "-" in pore pressure distribution contour is positive pore pressure. 


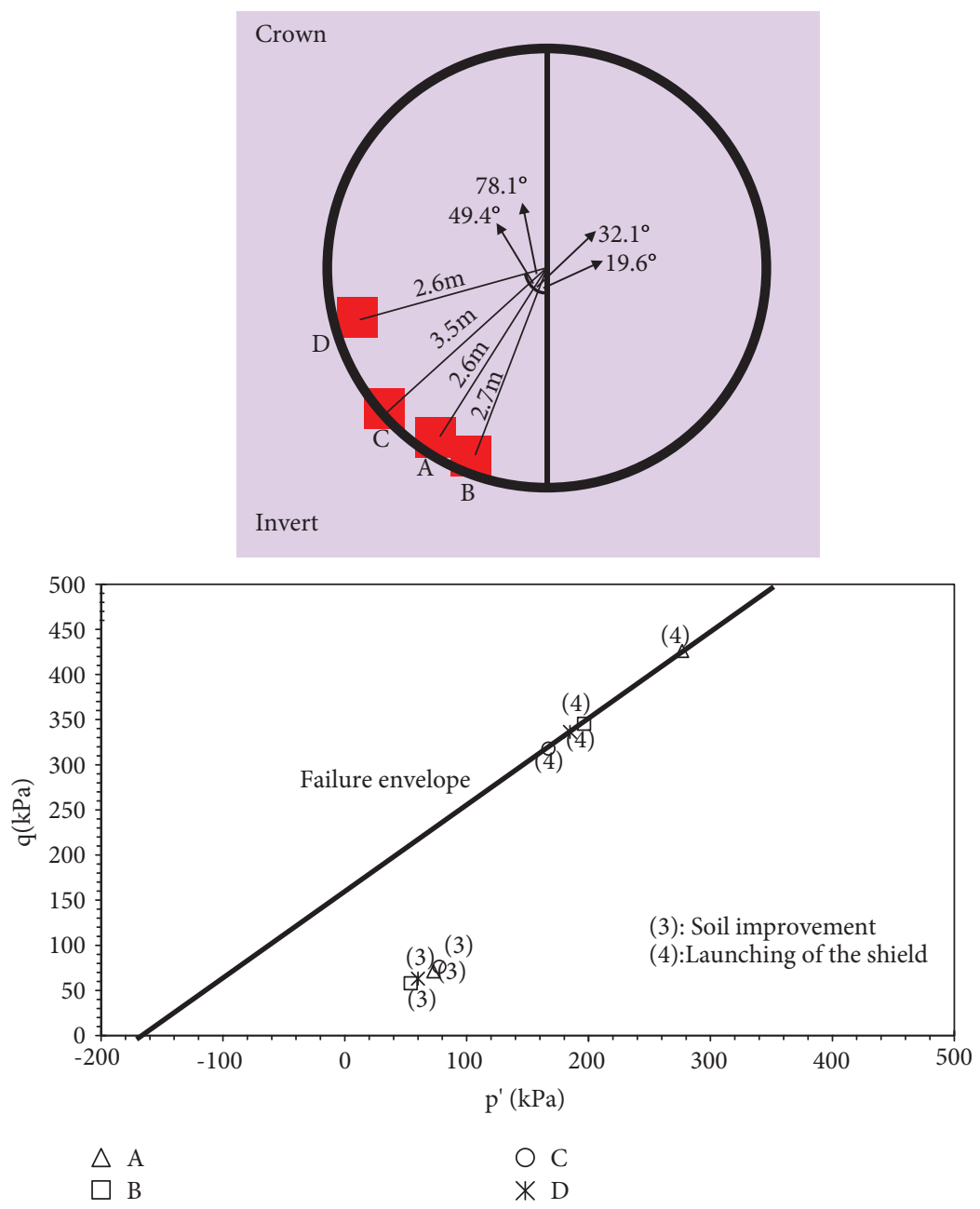

FIGURE 10: Effective stress path and failure envelope for failure caused by launching of a shield for soils immediately behind the wall.

initially assembled and launched at the shaft of one end and then the excavation of the tunnel to gradually continue until reaching the other end of the tunnel. Once the tunnel excavation has been completed, the shield is docked in the shaft at the other end of the tunnel and then disassembled. A schematic drawing of the launching of a shield tunnelling activity is presented in Figure 1. To prevent water ingress leading to failure during launching of the shield, the soil must be grouted to form a grouted box outside the shaft. In this manner, soil strength and stiffness are increased and soil permeability is reduced to allow the break-in of the retaining wall of the shaft to be delivered for shield launching and eliminate the opportunity for failure caused by water ingress.

A simulation of the failure caused by water ingress via launching of the shield is conducted first. Senthilnath [7] has simulated underground docking of a tunnelling boring (shield) machine, which involves a mechanism similar to the mechanism of launching; however, the goal was to simulate docking of the machine in a shaft constructed in low permeable rock bed without failure, which differs from the goals of this paper.
Referring to Hsiung et al. [8], part of the same excavation is assumed as the pit used for launching of the shield. The pit is retained by a 0.9 -m-thick and 32-m-deep reinforcement concrete diaphragm wall with additional four-level horizontal struts. The maximum excavation level reaches $16.8 \mathrm{~m}$ below ground level. Figure 2 presents the cross section and ground profile of the excavation. A half-symmetric model for the excavation is made, and the size of the model is set as $80 \mathrm{~m} \times 60 \mathrm{~m} \times 60 \mathrm{~m}$. In principle, the boundaries are established at places that are not affected by any construction activity or where the ground is sufficiently stiff. The model consists of 93,847 ten-node tetrahedral elements with a total of 132,018 nodes. The "very fine" mesh is applied for the improved soil zone, and the "normal" mesh setting is chosen for the rest. The 3-dimensional model is presented in Figure 3, and analytical software PLAXIS3D with version 2016 is adopted for the analyses. The diameter of the tunnel eye used for launching of the shield that must fit the outer diameter of the shield on the retaining wall is assumed to be $6.1 \mathrm{~m}$. The depth of the center of the tunnel eye is set at $12.95 \mathrm{~m}$ below surface level. As stated above, the soils outside the pit must be improved to reduce their 

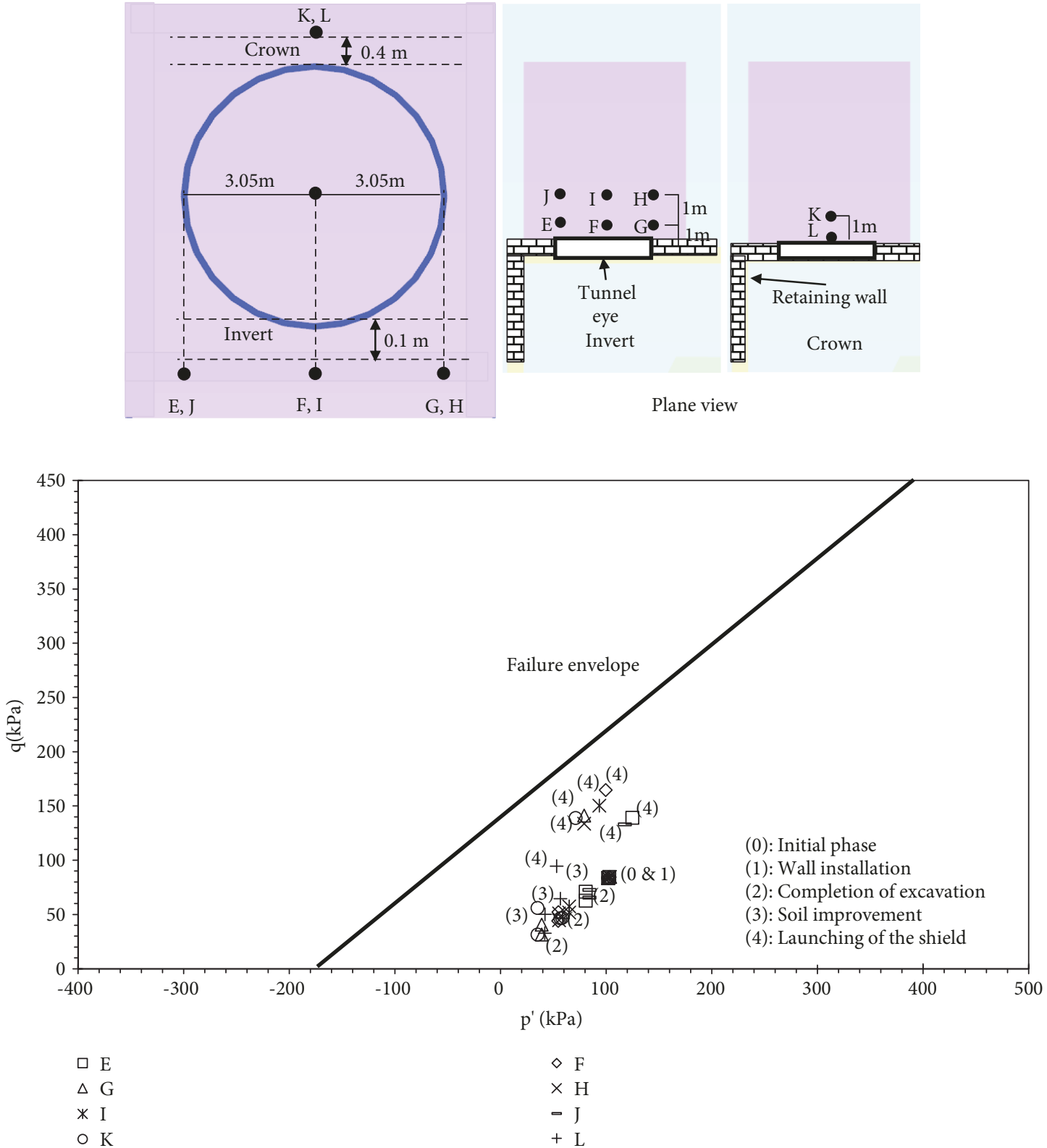

FIGURE 11: Effective stress path and failure mechanism for soils at various locations outside the pit.

permeability and increase their strength; the soil improvement zone outside the pit is assumed to be $10 \mathrm{~m}$ long, $9 \mathrm{~m}$ wide, and $13.6 \mathrm{~m}$ thick. Figure 4 presents the assumed details of the tunnel eye and the soil improved zone in the model.

It is assumed that groundwater is allowed to flow into the model from all directions, except at the surface level and inside the pit. The boundary conditions for the water are shown in Figure 5. The water flow is closed in the Ymin and Zmax planes but not the other planes.

Because the focus is the failure mechanism caused by water ingress due to launching of the shield, the seepage function must be used instead of elastic-plastic analyses. Moreover, the soil profile is the same as that of Hsiung et al. [8], and the constitutive model that gives special consideration to small strain behaviour, HS-small (HSS), was selected for original sandy soils; however, the elasticperfect plastic Mohr-Coulomb model was chosen instead for clays and improved soils because of the limits of the available input parameters, the input parameters of improved soils are referred to Dano et al. [9]. The linear-elastic model is chosen for simulation of the reinforcement concrete diaphragm wall. Node-to-node anchor elements and node-tofixed end anchor elements are used for struts in the transverse direction and the longitudinal direction, respectively. Table 2 presents details on the input parameters of the soil and structures used for the analyses.

In engineering practice, the highly permeable soils outside the pit shall be improved by various methods at various levels, with achieving certain level of undrained shear strength of 


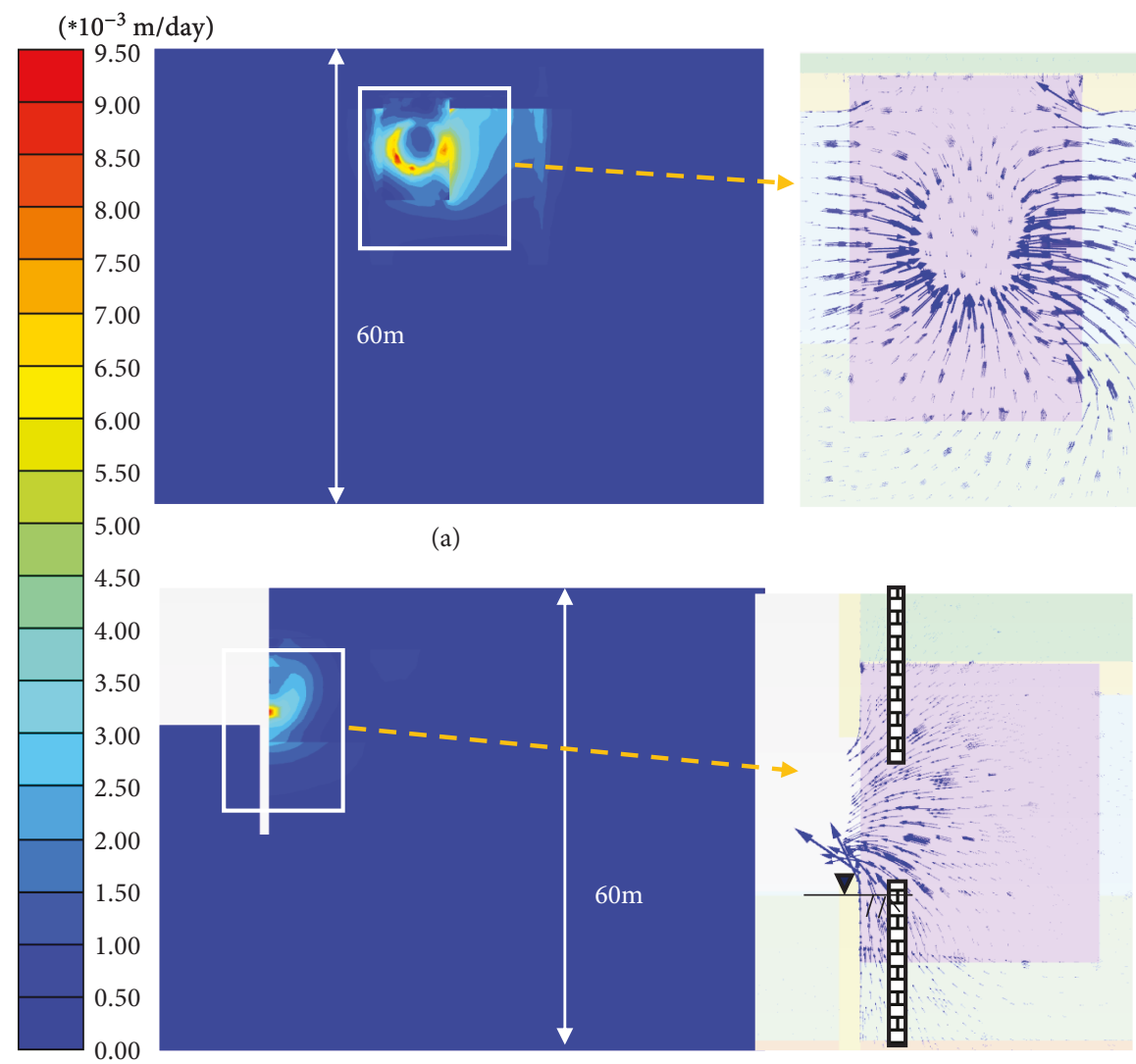

(b)

Figure 12: Flow line at failure caused by launching of a shield. (a) Transverse direction. (b) Longitudinal direction.

improved soils, in general, as reported in [9-11]. However, to run fully coupled seepage analyses, the effective strength parameters of improved soils must be given; moreover, as noted by Dano et al. [9], for improved soils, the effective friction angle is one to four degrees higher than that of the original soils. By using the "triaxial test" function implemented in PLAXIS3D, it is recommended that $100 \mathrm{kPa}$ of equivalent cohesion force and 34 degrees of equivalent effective friction angle shall be determined for improved soils based on $120 \mathrm{kPa}$ of undrained shear strength.

To further reduce the running time of analyses, the wall installation and main excavation of the pit are assumed to be "wished-in-place (WIP)" analyses, i.e., displacements induced by both stages are ignored. Table 3 presents the construction phases used for simulation of the launching of the shield.

\section{Results and Discussion}

Figure 6 presents the failure points caused by launching of the shield, and all failure soils are presented in terms of the angle to the six o'clock direction and the distance to the tunnel center. The angle is in the range of 19.6 to 78.1 degrees in the clockwise direction, and the distance remains the same with the radius of the tunnel eye $(3.05 \mathrm{~m})$. All failure soils are located immediately behind the wall, mainly at the invert of the tunnel (the points in red, named "A," "B," "C," and " $D$ "); further discussion regarding the locations of the failure soils are provided in a later section.

Figure 7 shows the pore pressure distribution at various stages for soils immediately behind the wall in the transverse direction. The pore pressure almost does not change until the completion of the main excavation. It is likely that the size of the excavation is not huge, with cut-off reinforcement concrete retaining walls, and a layer of impermeable clayey material is found at the depth near the wall toe (at $28.5 \mathrm{~m}$ to 30 . $5 \mathrm{~m}$ below ground level); the necessary dewatering inside the excavation could thus lead to very limited impacts on the pore pressure outside the excavation. However, the pore pressure is significantly reduced in the zone in which the wall (tunnel eye) is broken for launching of the shield; although the soil has been improved and the soil permeability, the strength, and the stiffness are all different for the original soils but not for others, such as Section D-D. Improvement most prominently affects the pore pressure at Section B-B, close to the invert of the tunnel, where the maximum difference is as significant as $100 \mathrm{kPa}$. The flush-in of groundwater into the pit is thus concluded to cause water relief and reduce the pore pressure of the soils at the back of the wall specifically in soils in the zone close to the tunnel eye.

To further demonstrate the impacts of groundwater on launching of the shield, the pore pressure distribution contour at various stages for soils outside the excavation in the longitudinal direction is presented in Figure 8. In the same 


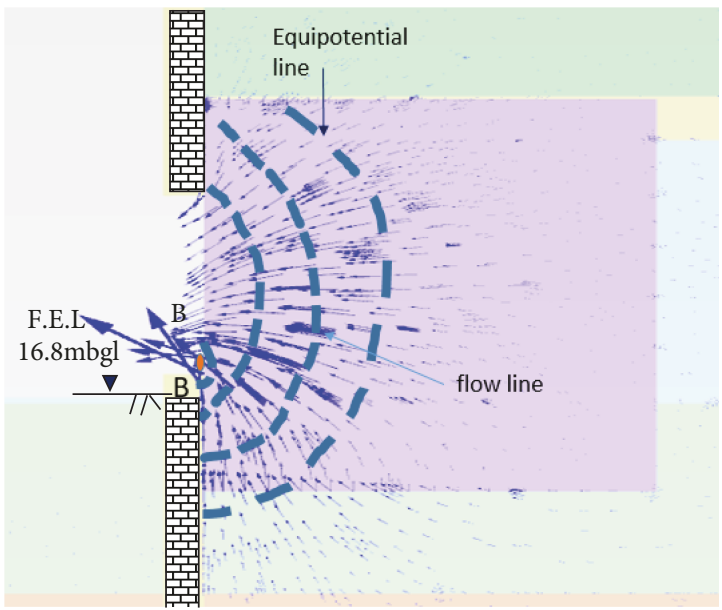

$$
\begin{aligned}
& \text { For point B } \\
& \text { Interpreted hydraulic } \\
& \text { gradient }(i) \\
& i=\frac{\Delta h}{L}=\frac{(11-0.8)}{5}=10.84 \\
& \begin{array}{l}
\text { Safety factor against piping } \\
(F S)
\end{array} \\
& F S=\frac{i_{\text {cr }}}{i}=\frac{1}{10.84}=0.09
\end{aligned}
$$

(a) Failure case $\left(\mathrm{C}^{\prime}=100 \mathrm{kPa} ; \Phi^{\prime}=34^{\circ} ; \mathrm{E}^{\prime}=120,000 \mathrm{kPa}\right.$ and $1 \times 10^{-6} \mathrm{~cm} / \mathrm{sec}$ of permeability $)$

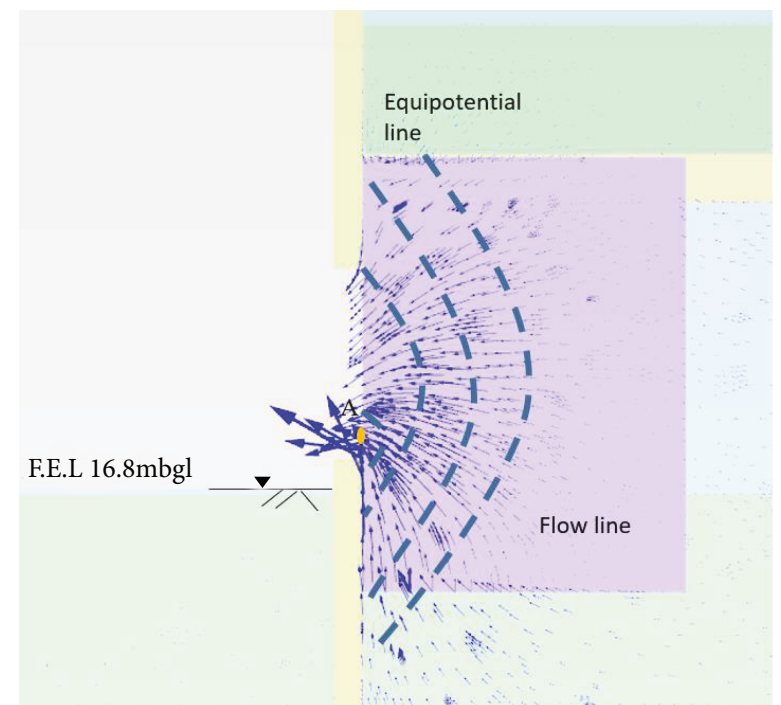

For point $\mathrm{A}$

Interpreted hydraulic gradient $(i)$

$i=\frac{\Delta h}{L}=\frac{(10-4)}{5}=1.2$

Safety factor against piping

$(F S)$

$F S=\frac{i_{c r}}{i}=\frac{1}{1.2}=0.833$

(b) Nonfailure case $\left(\mathrm{C}^{\prime}=200 \mathrm{kPa} ; \Phi^{\prime}=34^{\circ} ; \mathrm{E}^{\prime}=169,000 \mathrm{kPa}\right.$ and $1 \times 10^{-6} \mathrm{~cm} / \mathrm{sec}$ of permeability $)$

FIGURE 13: Schematic drawing of flow net and safety factor against piping calculation.

figure, the pore pressure of soils located at 2, 4, 8, and $12 \mathrm{~m}$ from the wall along the depth are also plotted; similar to the pore pressure distribution shown in the transverse direction, the pore pressure in this plot remains almost the same during the main excavation stage. Due to the flush-in of groundwater, a decrease in pore pressure as great as $60 \mathrm{kPa}$ is observed at the invert of the tunnel when compared with the stress at the initial stage at the same location for the pore pressure at $2 \mathrm{~m}$ away from the wall. Launching of the shield only influences the pore pressure at approximately $7 \mathrm{~m}$ to $18 \mathrm{~m}$ below the surface level at a degree that is slightly more than the tunnel eye zone, as shown in Figure $8(\mathrm{c})$. However, once the distance is farther away, the impact is gradually reduced. Until a distance of $12 \mathrm{~m}$ from the wall, the launching of the shield does not cause any change in pore pressure.

The major influence on pore pressure distribution is found at a similar depth as the invert of the tunnel, according to the previous discussion; thus, Figure 9 presents the pore pressure change contour at the said depth of the soils. As shown in Figure 9, regardless of the section, decreases in pore pressure are observed in the locations spanning from immediately next to the wall to $20 \mathrm{~m}$ from the wall but remain unchanged for grounds residing at more than $20 \mathrm{~m}$ from the wall. It can also be inferred from Figure 9 that Section B-B has the largest change, whereas Section D-D does not exhibit any change at distances greater than $10 \mathrm{~m}$ from the wall, because this section is not within the tunnel eye zone.

The effective stress path and the failure mechanism of soils outside the excavation are examined. Figure 10 shows the various soil elements at various locations surrounding the tunnel eye from the view of the transverse direction for soils behind the wall together with the effective stress path of each soil element and its relative locations within the failure envelope. The labels " $p$ "” and " $q$ " indicate the mean effective stress and the deviatoric stress, respectively. Stress relief is observed during the main excavation stage, leading to 


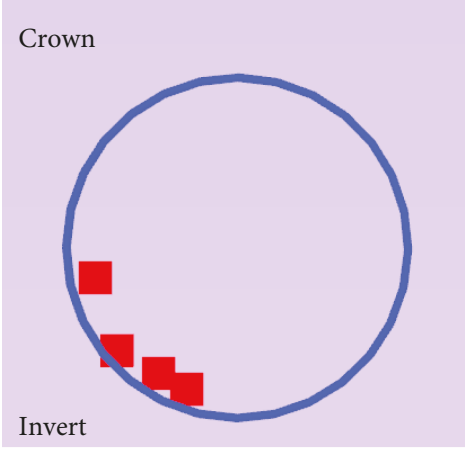

(a1)

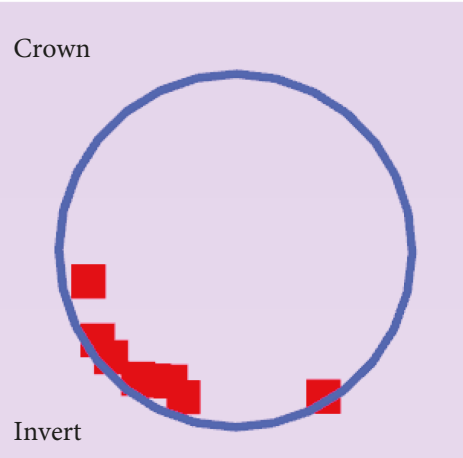

(b1)

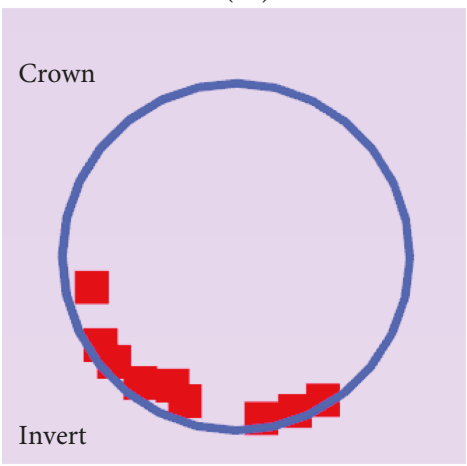

(c1)

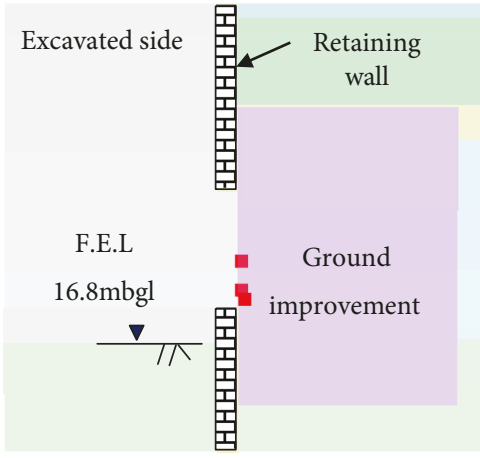

(a2)

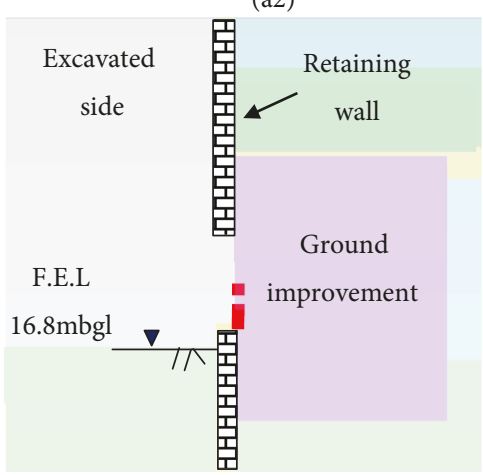

(b2)

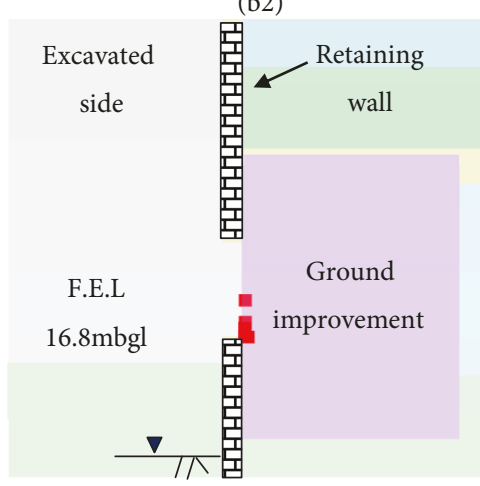

(c2)

FIGURE 14: Impacts from various soil permeability on failure caused by launching of a shield. Note: "1" means transverse direction and "2" means longitudinal direction. (a) $10^{-6} \mathrm{~cm} / \mathrm{sec}$, (b) $10^{-5} \mathrm{~cm} / \mathrm{sec}$, and (c) $10^{-4} \mathrm{~cm} / \mathrm{sec}$.

reductions of p' and q. The stress status does not change during the soil improvement stage, and it is presumed that soil improvement is conducted in a limited zone and does not change the stress significantly afterwards, even though the soil properties have been fully changed after improvement. Once the shield is launched, the effective stress of the soils at points $\mathrm{A}$ to $\mathrm{D}$ (refer to Figure 6 for locations) reaches the failure status; therefore, these points lie on the failure envelope, as shown in Figure 10. The flush-in of groundwater significantly increases the vertical stress but causes a very limited increase in the effective stress in the lateral direction and is expected to be the reason for the simultaneous increases in p' and q from phase 3 to phase 4.

The effective stress path and failure mechanism of soils at additional locations are also examined from the views in both the transverse and longitudinal directions, as presented in
Figure 11. Similarly, the soil elements closer to the excavation have more significant stress relief at the main excavation stages, such as points $\mathrm{E}, \mathrm{F}, \mathrm{G}$, and $\mathrm{L}$, rather than points $\mathrm{H}$, I, J, and K. Moreover, because of the flush-in of groundwater, both p' and q increase via a similar trend, where the stress in the soils closer to the wall changes but does not reach failure, as shown in Figure 11.

Figure 12 shows the flow line directly output from the simulation model in both the transverse direction and the longitudinal direction. The size of the arrow implies the quantity of water flow. In either the transverse or longitudinal direction, water flows into the pit mainly in the invert part of the tunnel, consistent with the observations of Moh and Hwang [6] and Ju et al. [12] from accidents caused by the launching and docking of the shield in the pit. This agreement further validates the accuracy of the numerical model 


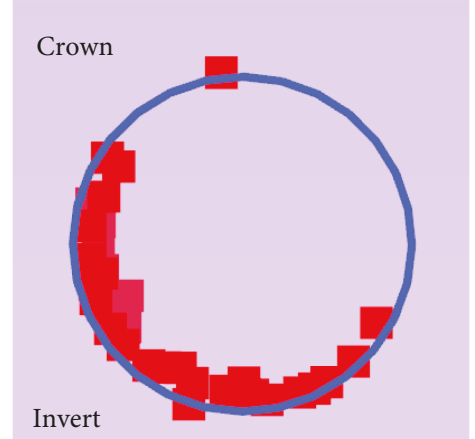

(a1)

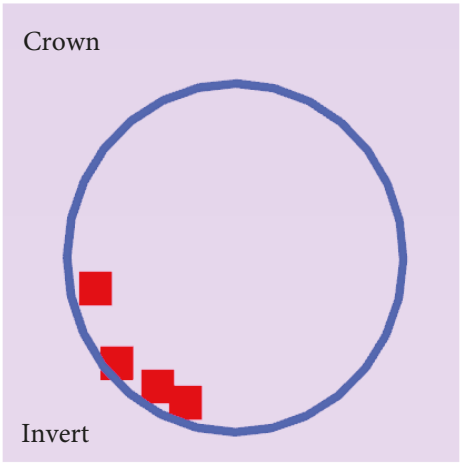

(b1)

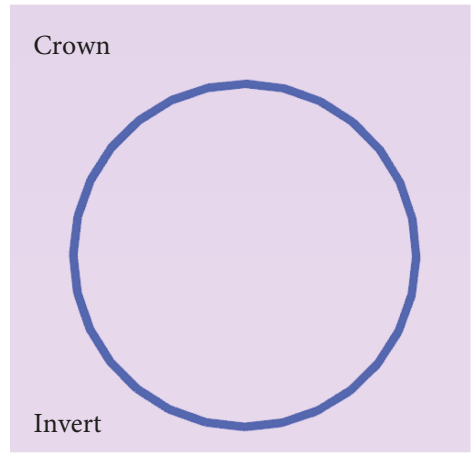

$(\mathrm{c} 1)$

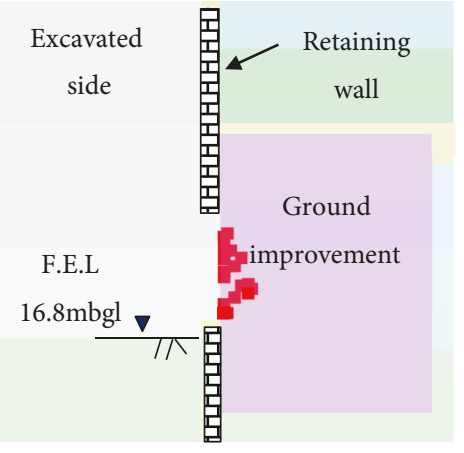

(a2)

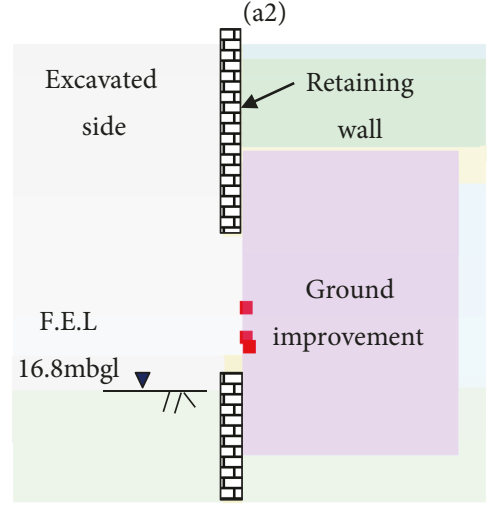

(b2)

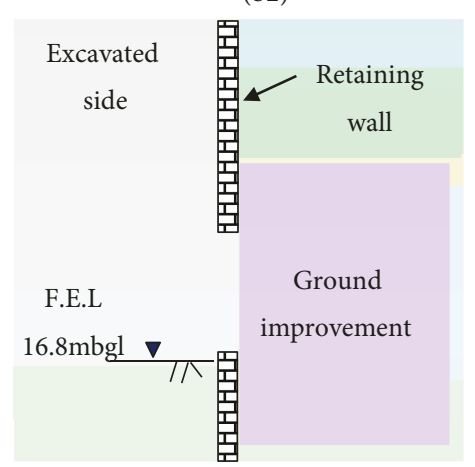

(c2)

FIGURE 15: Impacts from various soil strength on failure caused by launching of a shield. Note: "1" means transverse direction and "2" means longitudinal direction. (a) $50 \mathrm{kPa}$ (cohesion), (b) $100 \mathrm{kPa}$ (cohesion), and (c) $200 \mathrm{kPa}$ (cohesion).

built in this study. It is anticipated that gravity causes most of the water flow from the invert part of the tunnel into the bottom of the pit. The predicted quantity of water flush into the pit is $0.1225 \mathrm{~m}^{3}$ per day, which is equivalent to $85 \mathrm{ml}$ per minute.

$\mathrm{Ou}[13]$ indicated that the excavation in highly permeable ground may lead to piping failure, which is also closely connected with groundwater, and Pratama and $\mathrm{Ou}$ [14] conducted a study using both numerical analyses and an empirical approach to interpret the safety factor against the piping. As indicated previously, the flow line caused by the launching of the shield can be presented, but the software used does not have the function to present the equipotential line and the flow net. Therefore, a personal judgement is required to allow the hydraulic gradient and the safety factor to be interpreted based on the pressure head and coordinates of the related nodes in the model. A schematic drawing of the flow net and the details of the safety factor against the piping calculation are presented in Figure 13(a). Accordingly, the factor is only 0.09 , which should lead to piping failure during the launching of the shield. However, potential of nonfailure case for safety against piping is examined also and it presents the safety factor is much higher but still less than 1 , as shown in Figure 13(b). It means potential of piping failure still exists for nonfailure case which is connected to different definitions and mechanism of failure in analyses. It is thus recommended that an additional check for safety factor against piping of any nonfailure case shall be considered.

To further evaluate the impacts from soil permeability, strength, and stiffness, parametric studies were conducted on 


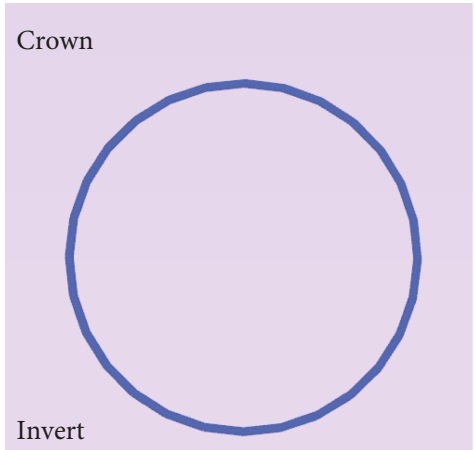

(a1)

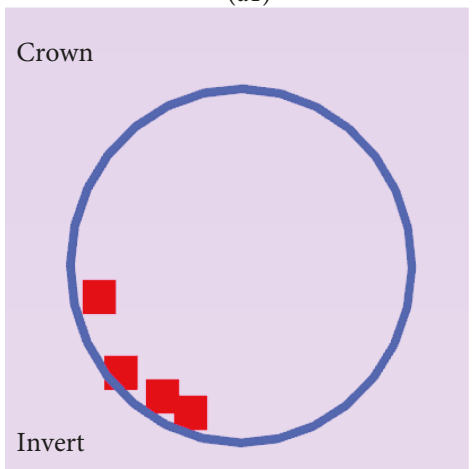

(b1)

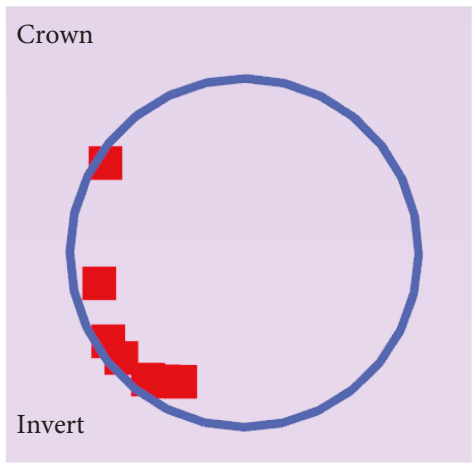

(c1)

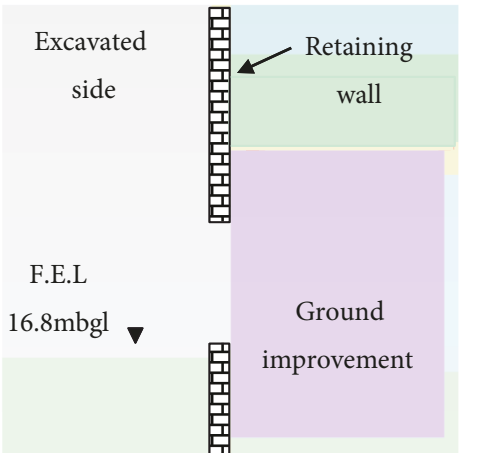

(a2)

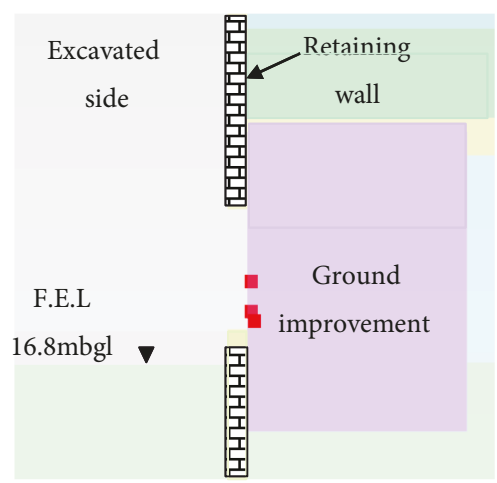

(b2)

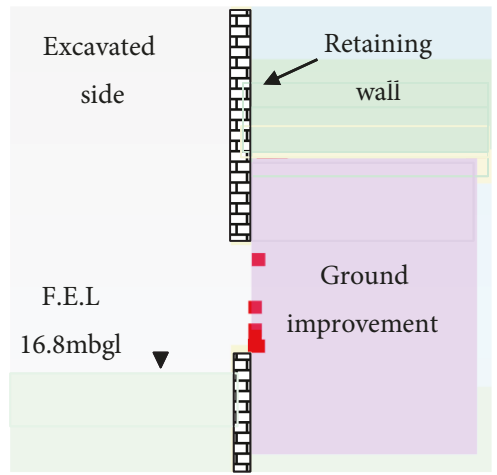

(c2)

FIGURE 16: Impacts from various soil stiffness (elastic modulus) on failure caused by launching of a shield for (a) $65 \times 10^{3} \mathrm{kPa}$, (b) $130 \times 10^{3} \mathrm{kPa}$, and (c) $260 \times 10^{3} \mathrm{kPa}$. Note: "1" means transverse direction and "2" means longitudinal direction.

geohazards and failure caused by groundwater. Figure 14 presents the failure soils in the model from the views of both transverse and longitudinal directions for the permeability of the improved soils with values of $10^{-6} \mathrm{~cm} / \mathrm{sec}, 10^{-5} \mathrm{~cm} / \mathrm{sec}$, and $10^{-4} \mathrm{~cm} / \mathrm{sec}$. More failure soils are found to be gradually associated with decreasing permeability, and it is suggested that permeability plays an important role in the control of soil failure. In addition, the failure of soil can be prevented if soil permeability can be reduced through the necessary soil improvement activities.

Figure 15 shows the improved soils with the cohesion force increasing from $50 \mathrm{kPa}$ to $200 \mathrm{kPa}$. As shown in Figure 15 , the soils are likely to fail if only $50 \mathrm{kPa}$ of cohesion exists; however, the status can change to "no failure" for $200 \mathrm{kPa}$ of cohesion. This is consistent with the conclusion of Dano et al. [9]: a higher cohesion force increases the failure strength of the soil and is the basis of such a phenomenon.
Impacts due to the elastic modulus of improved soils are also examined. The elastic modulus of the improved soils is assumed to be $65,000 \mathrm{kPa}, 130,000 \mathrm{kPa}$, and $260,000 \mathrm{kPa}$. Soils with an elastic modulus of $65,000 \mathrm{kPa}$ can reach the "no failure" status; however, more failure soils were observed once the elastic modulus of the improved soils increases, as shown in Figure 16. Because the failure strength of improved soils remains unchanged, it is likely that a very small strain can easily cause soils to reach failure once the improved soil becomes very stiff. Therefore, one can draw a conclusion that a very high elastic modulus of the improved soil may not be sufficient to prevent the failure of soils due to groundwater during underground excavation.

\section{Conclusions}

The following conclusions can be drawn based on this study: 
(1) It is well recognised that groundwater plays an important role in urban underground excavation and very often leads to catastrophic hazards. Such hazards include geotechnical failure caused by leakage of the tunnel eye via launching and docking of the shield, failure of cross-passage construction for tunnelling, and failure of the retaining wall or diaphragm wall caused by water ingress for deep excavation as well as rupture of a water main or sewer caused by any construction activity of deep excavation or nearby tunnelling, especially for highly permeable ground with a high groundwater level

(2) For geohazards induced by groundwater in urban underground excavation, leakage and failure of the tunnel eye during launching of the shield were selected for further simulation using finite element analyses; this important work had not been previously performed. A three-dimensional model was built to simulate the pore pressure distribution, the quantity of flush-in groundwater, the flow direction, and the failure of soils during launching of the shield. As failure of cross passage and leakage of diaphragm wall related to underground water also often lead to catastrophic accidents, simulations of both matters can be considered to be delivered to understand related behaviours and mechanism in the future

(3) Considering current assumptions and the results of the study, it was concluded that most of the failed soils are located at the invert of the tunnel, immediately behind the wall. According to site observations, it is likely that gravity is the cause of such failure phenomena. However, findings also indicate that all soils located $1 \mathrm{~m}$ from the wall remain stable and do not fail

(4) The pore pressure of soils is significantly reduced during launching of the shield as the ingress of water simultaneously releases the pore pressure of the soils behind the wall. The predicted quantity of water through the tunnel eye during launching of the shield is $85 \mathrm{ml}$ per minute. According to the evaluation of the changes in the mean effective stress ( $p$ ') and the deviator stress (q), both p' and $q$ increase during the process of shield launching

(5) After examining the potential of piping, it is suggested that the current arrangements of improved soils outside the pit would not prevent piping failure during the launching of the shield. However, an additional check for safety factor against piping of any nonfailure case shall be considered due to different definitions and mechanism of failure

(6) The results of a parametric study of the impacts of the permeability, strength, and stiffness of improved soils on the geohazards and soil failures caused by groundwater ingress suggested that the reduction in soil permeability and the increase in cohesion force can successfully prevent the opportunities of failure.
In contrast, a very high elastic modulus may not help to prevent the failure of soils

\section{Data Availability}

The data used to support the findings of this study are available from the corresponding author upon request.

\section{Conflicts of Interest}

The author declares no conflicts of interest.

\section{References}

[1] H. Wanger and M. Knights, "Risk management of tunneling works," in Workshop on safety in tunnels and underground structure, pp. 8-9, International Tunnel Association, Riyadh, 2006.

[2] British Tunnel Society, The Joint Code of Practice for Risk Management of Tunnel Works in UK, British Tunnel Society, 2003.

[3] S. Degn Eskesen, P. Tengborg, J. Kampmann, and T. H. Veicherts, "Guidelines for tunnelling risk management: international tunnelling association, working group no. 2," Tunnelling and Underground Space Technology, vol. 19, no. 3, pp. 217-237, 2004.

[4] GEO, "Geotechnical risk management for tunnel works," in GEO Technical Guidance Note No. 25 (TGN25), Hong Kong, China, 2005.

[5] The International Tunnelling Insurance Group, A Code of Practice for Risk Management of Tunnel Works, International Tunnel Association, 2006.

[6] Z. C. Moh and R. N. Hwang, "Lessons learned from recent MRT construction failure in Asia Pacific," Journal of Southeast Asian Geotechnical Society, vol. 38, pp. 122-137, 2007.

[7] G. T. Senthilnath, "Mid- tunnel undergound docking of tunnel boring machine in Singapore," in Challenges and Innovation to Geotechnics. Proceedings of the 8th Asian Young Geotechnical Engineers Conference, Astana, Kazakhstan, August 2016.

[8] B. C. B. Hsiung, K. H. Yang, W. Aila, and C. Hung, "Threedimensional effects of a deep excavation on wall deflections in loose to medium dense sands," Computers and Geotechnics, vol. 80, pp. 138-151, 2016.

[9] C. Dano, P. Y. Hicher, and S. Tailliez, "Engineering properties of grouted sands," Journal of Geotechnical and Geoenvironmental Engineering, vol. 130, no. 3, pp. 328-338, 2004.

[10] Y. S. Fang, C. C. Kao, J. Chou, K. F. Chain, D. R. Wang, and C. T. Lin, "Jet grouting with the superjet-midi method," Proceedings of the Institution of Civil Engineers - Ground Improvement, vol. 10, no. 2, pp. 69-76, 2006.

[11] B. C. B. Hsiung, "Field performance of an excavation using sleeve grouting," Proceedings of the Institution of Civil Engineers-ground improvement, vol. 162, no. 4, pp. 175-183, 2009.

[12] H. Ju, Y. S. Fang, W. C. Huang, and C. Liu, "Rescue and rehabilitation of damaged subway shield tunnels," Sino Geotechnics, vol. 155, pp. 1-14, 2018.

[13] C. Y. Ou, Deep Excavation: Theory and Practice, Taylor \& Francis, Netherlands, 2006.

[14] I. T. Pratama and C. Y. Ou, "Analysis of sand boiling failure in deep excavation," in Proceedings of the 2nd International 
Symposium on Asia Urban, Changsha, Hunan, China, November 2017.

[15] S. Y. Dao, Application of numerical analyses for deep excavations in soft ground, [Ph.D. thesis], National Kaohsiung University of Applied Sciences, Kaohsiung, Taiwan, 2015.

[16] H. S. Liao, "Discussion of design and construction of highpressure jet grouting," in Presented in 19th workshop of Sino Geotechnics Foundation, Kaohsiung, Taiwan, August 2006. 

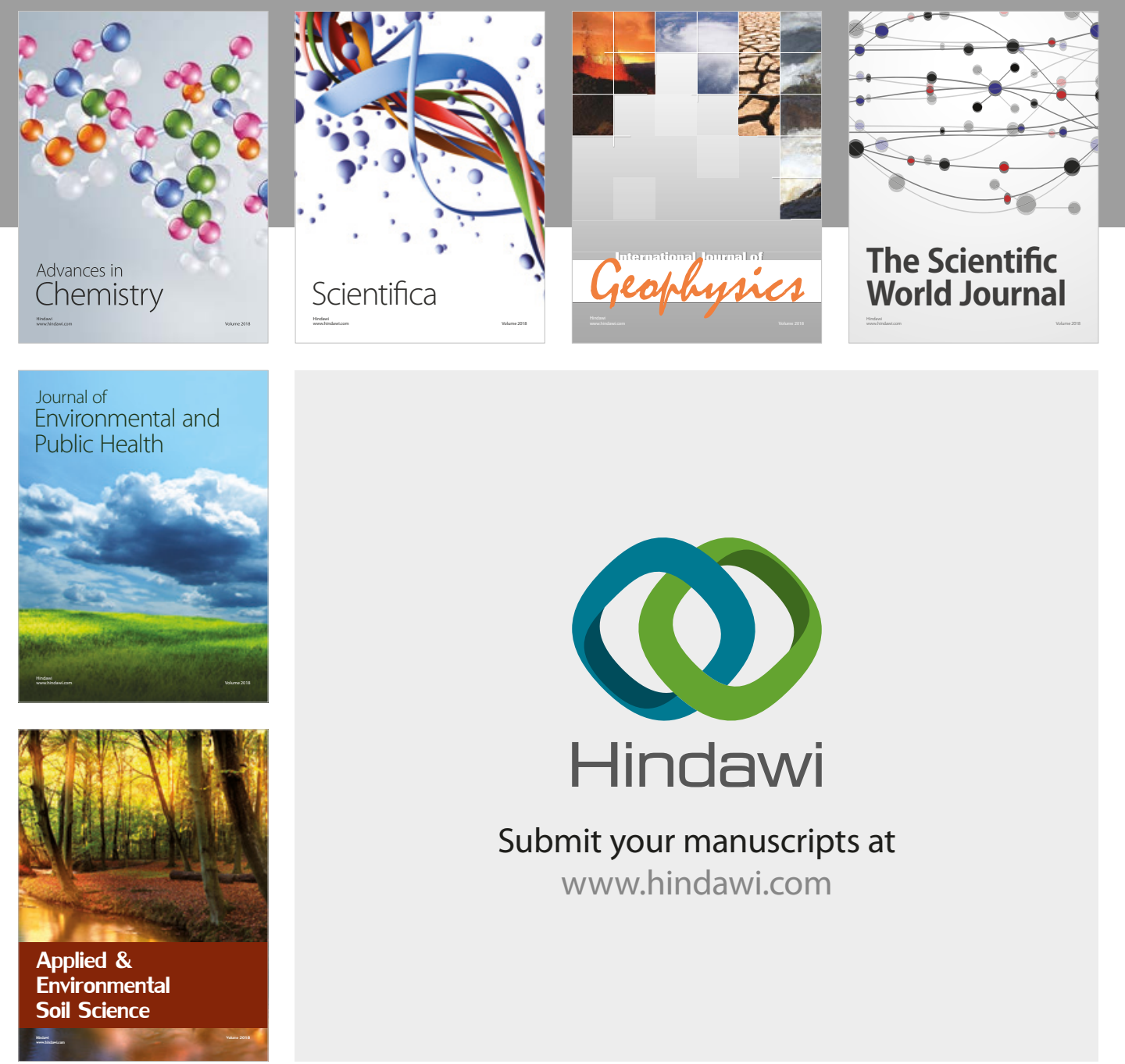

The Scientific

\section{World Journal}
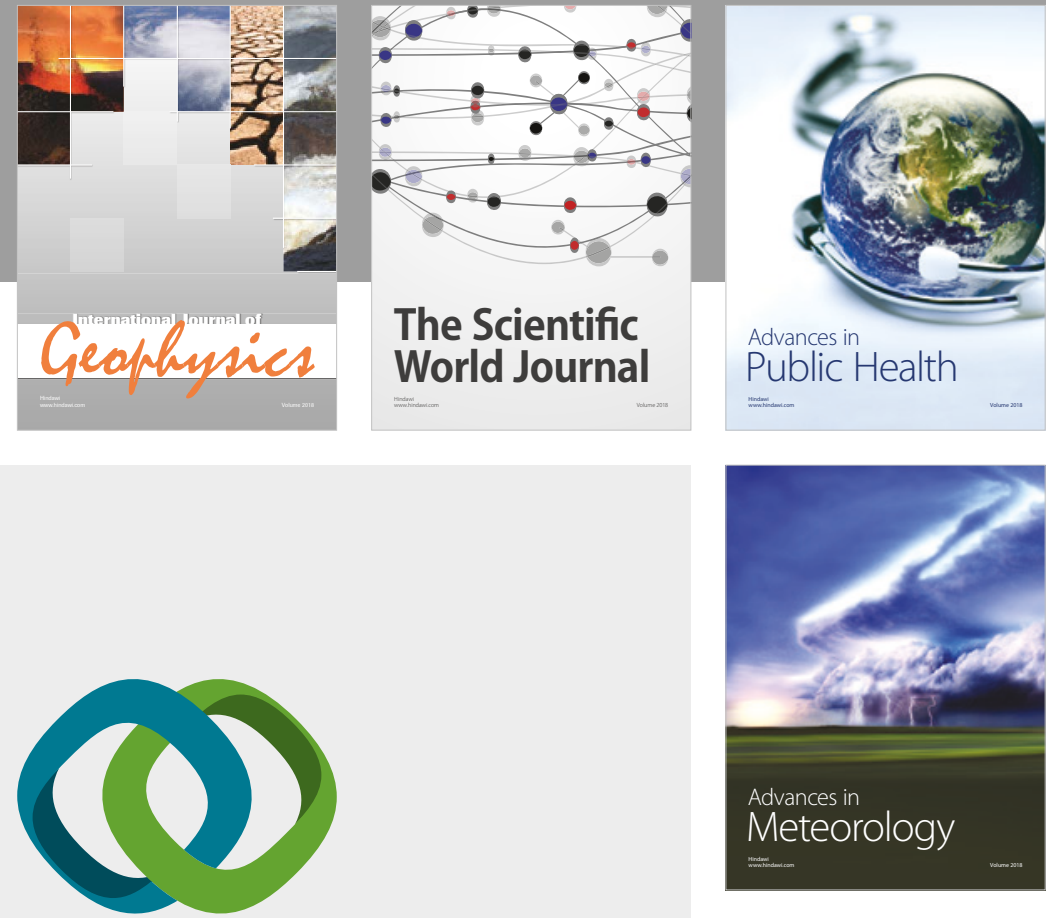

Advan

Public Health

\section{Hindawi}

Submit your manuscripts at

www.hindawi.com
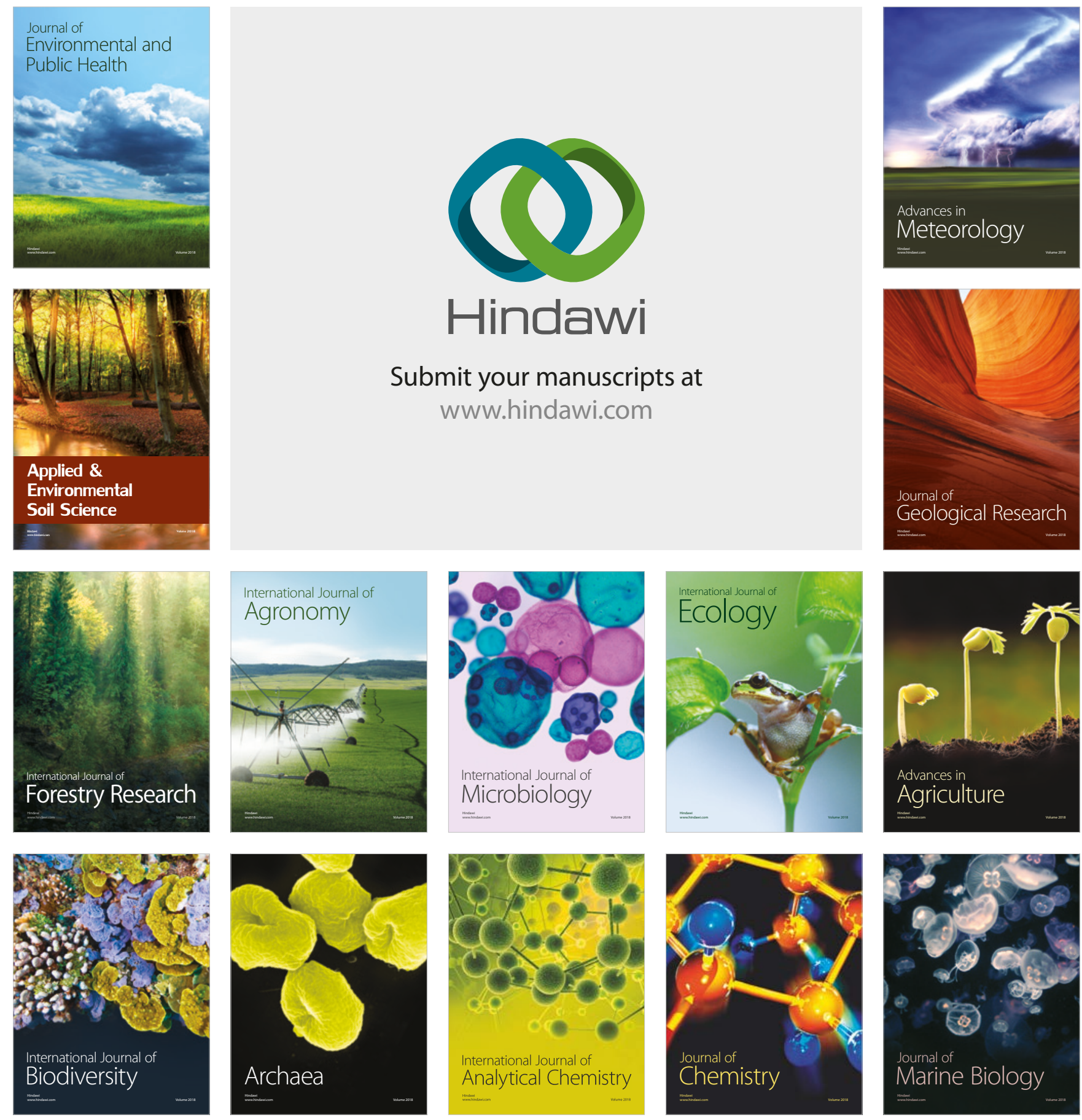